\title{
EL DERECHO PROCESAL CONSTTTUCIONAL A INICIOS DEL SIGLO XXI EN AMÉRICA LATINA
}

\author{
The procedural constitucional law to the beginning \\ of the XXI century in Latin America
}

\author{
Humberto Nogueira Alcalá ${ }^{1}$ \\ Profesor de Derecho Constitucional, \\ Universidad de Talca (Chile) \\ nogueira@utalca.cl
}

RESUM EN: A través del presente artículo se analiza la emergencia y desarrollo del derecho procesal constitucional en latinoamérica y su estado actual desde la perspectiva de su desarrollo académico, el debate sobre sus contenidos y su interdependencia o autonomía respecto del derecho procesal y del derecho constitucional.

PALABRAS CLAVE: Derecho procesal constitucional. Disciplina jurídica. Naturaleza jurídica.

ABSTRACT: Through this article examines the emergence and development of procedural constitutional law in Latin A merica and its constitutional status from the perspective of their academic development, the debate about its contents and their interdependence or autonomy from the procedural law and constitutional law.

KEY WORDS: Procedural constitutional law. Legal discipline. Legal nature.

1 El autor es doctor en derecho constitucional por la Universidad Católica de Lovaina La Nueva, Bélgica. Profesor Titular de Derecho Constitucional y Director del Centro de Estudios Constitucionales de Chile, Campus Santiago, Universidad de Talca. Presidente de la A sociación Chilena de Derecho Constitucional y Vicepresidente del Instituto Iberoamericano de Derecho Procesal Constitucional. Artículo presentado el 15 de marzo de 2009 y aprobado el 20 de mayo de 2009. 


\section{LA UTILIZACIÓN DEL VOCABLO DERECHO PROCESAL CONSTITUCIONAL, LOS ANTECEDENTES HISTÓ RICOS Y DOCTRINALES Y EL NACIMIENTO DE LA DISCIPLINA JURÍDICA}

\subsection{El uso del vocablo por Niceto Alcalá Zamora y Castillo}

El uso del concepto de derecho procesal constitucional surge en la década del 40 del siglo XX, siendo el jurista y procesalista español Niceto A Icalá Zamora y Castillo su creador, en sus obras de exilio en Argentina y México.

El vocablo fue utilizado por primera vez por Niceto Alcalá Zamora y Castillo, exiliado en A rgentina, el cual lo utiliza en su libro Ensayos de derecho procesal (civil, penal y constitucional), publicado en Buenos A ires en 1944, reiterándolo en artículo publicado en la Revista de Derecho Procesal, editada en Buenos Aires por Hugo Alsina (año III, 2 Parte, 1945, p. 77).

Niceto Alcalá Zamora y Castillo que luego emigra a M éxico contratado por la Universidad Nacional Autónoma de México, en su obra Proceso, autocomposición y autodefensa, ${ }^{2}$ sostiene que Kelsen constituye el fundador del derecho procesal constitucional. ${ }^{3}$

\subsection{Los antecedentes históricos del derecho procesal constitucional}

Dentro de las fuentes próximas del derecho procesal constitucional concordamos con Néstor Pedro Sagüés, en lo que denomina los "tres cumpleaños del derecho procesal constitucional": 4 a habeas Corpus Amendment Act Inglesa de 1679, en que se regula con detalle un primer proceso constitucional que garantiza el derecho fundamental a la libertad personal, el de Habeas Corpus; el caso Merbury vs. Madison, resuelto por la Corte Suprema Norteamericana el 24 de febrero de 1803, que institucionaliza el sistema judicial de control de constitucionalidad en los Estados Unidos de Norteamérica, aun cuando este no será asumido de inmediato como una práctica sostenida de la Corte Suprema norteamericana, pasando varias décadas, hasta que se asuma efectivamente y realmente en el sistema judicial norteamericano en la segunda mitad del siglo XIX; el tercer antecedente relevante para el derecho procesal constitucional y el cual acelera la reflexión sobre la materia de la jurisdicción constitucional, y

2 Alcalá-Zamora y Castillo, Niceto (1947). Proceso, autocomposición y autodefensa (contribución a los fines del proceso). Primera edición, México.

3 Alcalá-Zamora y CAstillo, Niceto (1991). Proceso, autocomposición y autodefensa (contribución a los fines del proceso). 3a ed. (México, UNAM), p. 215.

4 SAGÜÉs, Néstor Pedro (2006). Derecho procesal constitucional. Logros y obstáculos (Buenos Aires, Ed. Ad-Hoc y Konrad Adenauer Stifftung), pp. 19-20. 
un cambio en el paradigma de Estado de derecho, pasando al desarrollo del Estado Constitucional, fue el nacimiento del Tribunal Constitucional como órgano especializado de control de constitucionalidad en la Constitución de Austria del $1^{\circ}$ de octubre de 1920, en el que juega un rol significativo Hans Kelsen.

\subsection{Los antecedentes doctrinales del derecho procesal constitucional}

Puede señalarse que en la doctrina fueron Hans Kelsen, Eduardo Couture, Piero Calamandrei y Mauro Cappeletti los que aportaron las bases para el nacimiento del derecho procesal constitucional.

Ya Niceto A lcalá Zamora y Castillo sostiene en su obra Proceso, autocomposición y autodefensa (contribución a los fines del proceso) que Kelsen constituye el fundador del derecho procesal constitucional (3a ed. México, UNAM, 1991, p. 215); lo que es también asumido por Fix Zamudio en su memoria de licenciado en la conclusión quinta de ella. Sin lugar a dudas, para ello se considera que fue integrante del equipo que elaboró el texto referente al Tribunal Constitucional austriaco incorporado en la Constitución de 1920, del cual fue magistrado entre 1921 y 1930, luego que se dictara y promulgara el 13 de junio de 1921, la Ley Federal sobre organización del Tribunal Constitucional, sin perjuicio de mantenerse en la cátedra universitaria en la Facultad de Derecho de Viena.

Hans Kelsen es el autor del primer estudio sistemático sobre la jurisdicción constitucional desarrollado en 1928 en su obra La garantie jurisdictionelle de la Constitution (La justice constitutionnelle), ${ }^{5}$ donde fundamenta y desarrolla en forma sistemática la existencia de una jurisdicción constitucional concentrada y especializada.

Eduardo Couture se refiere al derecho procesal constitucional en su trabajo Las garantías constitucionales del proceso civil, publicado en el libro Estudios de Derecho Procesal en Honor de Hugo Alsina (Buenos Aires, 1946, pp. 158-173), como asimismo en su obra clásica Fundamentos del Derecho Procesal Civil, cuya primera edición es de 1947, donde dedica la tercera parte del tomo I a los casos del Derecho Procesal Constitucional. A simismo, se le considera el padre del Derecho Constitucional Procesal, el cual comprende el estudio de las garantías constitucionales de acceso a la jurisdicción o tutela judicial efectiva y las reglas sustantivas y adjetivas del debido proceso.

Piero Calamandrei, distinguido procesalista y luego profesor de derecho constitucional italiano en la postguerra, realizará aportaciones significativas al posterior desa-

Ver en Revue de Droit Public en France et a l'Étranger, Paris, 1928, pp. 52-143. Traducido al español por TAMAYO Y SALMORÁn, Rolando (1974), "La garantía jurisdiccional de la Constitución. (La justicia Constitucional)", en Anuario Jurídico, I, (M éxico, UNAM), pp. 471-515. 
rrollo del derecho procesal constitucional al establecer los fundamentos de la jurisdicción constitucional italiana en su obra La Illegittimita constituzionale delle leggi nel processo civile, ${ }^{6}$ la cual fue posteriormente, en 1962, traducida al español. ${ }^{7}$ A simismo, el autor aborda la materia en tres artículos: "Potere Giudiziario e Suprema Corte Costituzionale", "La Illegittimita constituzionale delle leggi nel processo civile", y "Corte Costituzionale e autoritá giudiziaria", publicados en Opere Giudiriche (Napoli, 1968, tomo III, pp. 215-225; 337-412; y 609-654), los cuales son traducidos al español por Sentís M elendo. ${ }^{8}$

Mauro Cappelletti, por su parte, aportará en el ámbito de la jurisdicción constitucional, que esta no sólo se refiere al control constitucional orgánico, sino que se amplía con la jurisdicción constitucional protectora de los derechos fundamentales o la jurisdicción constitucional de las libertades, lo que precisa en su obra La giurisdizione costituzionale delle liberta (Giuffrè, Milano, 1955), la que será traducida al español por el propio Fix Zamudio como La jurisdicción constitucional de la libertad (con referencia a los ordenamientos alemán, suizo y austriaco). ${ }^{9}$ A demás, el maestro italiano agrega el necesario estudio del derecho procesal trasnacional o Jurisdicción constitucional trasnacional, ${ }^{10}$ materia que trata también en su artículo "Justicia Constitucional supranacional", traducido por Luis Dorantes Tamayo y publicado en la Revista de la Facultad de derecho de M éxico N 110 , mayo-agosto, tomo XXVIII, M éxico, 1978, pp. 337 y ss.

\subsection{El desarrollo del derecho procesal constitucional como disciplina jurídica y su estudio sistemático por Héctor Fix Zamudio}

Es, sin duda, el maestro Héctor Fix Zamudio, discípulo de Alcalá Zamora y Castillo, quien desarrollará y sistematizará el derecho procesal constitucional como disciplina jurídica, cuyo primer trabajo fue su tesis de licenciado en derecho en 1955, denominada "La garantía jurisdiccional de la Constitución mexicana (ensayo de una estructuración procesal del amparo)", Facultad de Derecho, UNAM , 1955, 180 páginas, defendida en enero de 1956; publicados dos de sus capítulos en la Revista La Justicia en $1956^{11}$ y luego el contenido completo en su obra El juicio de Amparo, Editorial Porrúa, México, 1964, pp. 5-70. Asimismo, en 1956, publica el artículo "La aportación de

\footnotetext{
Obra editada por CEDAM, Padova, Italia, 1950.

7 Incorporada al texto de Calamandrel Estudios sobre el proceso civil, Buenos Aires, 1962, pp. 21-120.

8 Calamandrel, Piero (1962). Estudios sobre el proceso civil. Traducción de Sentís M elendo, Ejea, pp. 23120 y $121-198$.

9 CAPPELLeTI, Mauro (1961). La jurisdicción constitucional de la libertad (con referencia a los ordenamientos alemán, suizo y austriaco). Instituto de Derecho Comparado-UNAM. Imprenta Universitaria, M éxico.

10 Cappelletm, Mauro (1984), "Necesidad y legitimidad de la justicia constitucional”, en Tribunales Constitucionales Europeos y Derechos Fundamentales. Madrid. Centro de Estudios Constitucionales, pp. 599-662.

11 El capítulo El Derecho Procesal Constitucional, en La Justicia, Tomo XXVII, Nos 309-310, enero-febrero, 1956, pp. 12300-12313 y 12361-12364; y el capítulo El Proceso Constitucional, en La Justicia, Tomo XXVII, Nº 317, septiembre de 1956, pp. 12625-12336.
} 
Piero Calamandrei al Derecho Procesal Constitucional (Revista de la Facultad de Derecho de México, Tomo VI, N²4, octubre-diciembre de 1956).

Ya en su tesis de licenciatura, Fix Zamudio consideraba la existencia de "una disciplina instrumental que se ocupa del estudio de las normas que sirven de medio para la realización de las disposiciones contenidas en los preceptos constitucionales, cuando estos son desconocidos, violados o existe incertidumbre sobre su significado; siendo esta materia una de las ramas más jóvenes de la Ciencia del Derecho Procesal, y por lo tanto, no ha sido objeto todavía de una doctrina sistemática que defina su verdadera naturaleza y establezca sus límites dentro del inmenso campo del Derecho". ${ }^{12}$

Fix Zamudio, en La garantía jurisdiccional de la Constitución mexicana (Ensayo de una estructura procesal del Amparo), se refiere al derecho procesal constitucional como aquel que se ocupa del examen de las garantías de la propia Ley Fundamental, y que están establecidas en el texto mismo de la norma suprema (p. 91).

Los aportes más maduros de Fix Zamudio sobre la materia se encuentran en su obra y que luego se publicará también por FUNDAP, Querétaro, en el año 2002, como asimismo en sus obras Derecho constitucional mexicano y comparado (2003), y La defensa de la Constitución en el ordenamiento mexicano (Ed. Porrúa, M éxico, 2006).

Fix Zamudio en La garantía jurisdiccional de la Constitución mexicana (Ensayo de una estructura procesal del Amparo), conceptualiza el proceso constitucional como "conjunto armónico y ordenado de actos jurídicos, en vista de la composición de la litis de trascendencia jurídica, que establece una relación de las partes con el juzgador y que se desenvuelve en una serie concatenada de situaciones". ${ }^{13}$

En Introducción al derecho procesal constitucional, Fix Zamudio vuelve sobre el concepto de derecho procesal constitucional, señalando que "tiene por objeto el análisis científico, desde la perspectiva de la teoría o doctrina general del proceso o del Derecho Procesal, de las garantías constitucionales establecidas por la Carta Federal de 1917, con sus numerosas reformas posteriores". ${ }^{14}$ En la misma obra, el autor precisa que "[... ] debemos estar conscientes que hay una presencia de las diversas disciplinas procesales respecto del derecho sustantivo que es relativamente reciente y que ese desprendimiento ha sido paulatino, comenzando por el derecho procesal civil y penal, y sólo posteriormente los derechos procesales administrativos, de trabajo, agrario, etc. y una de las ramas más modernas, sino es que debe considerarse la más actual, es precisamente el derecho procesal constitucional". ${ }^{15}$

12 Fix-ZAmudio, Héctor (1955). La garantía jurisdiccional de la Constitución mexicana (Ensayo de una estructura procesal del Amparo) (M éxico, D.F. UNAM), p. 57.

13 Fix-Zamudio, Héctor (1955). La garantía jurisdiccional de la Constitución mexicana (Ensayo de una estructura procesal del Amparo) (M éxico, D.F. UNAM), p. 106.

14 Fix-ZAmudio, Héctor (2002). Introducción al Derecho Procesal Constitucional (Ed. Querétaro, FUNDAp), pp. 113-114.

15 Fix-Zamudio, Héctor (2002), ob. cit., pp. 19 y ss. 
Finalmente, Fix Zamudio en sus Breves reflexiones sobre el concepto y contenido del derecho procesal constitucional, nos señala que el derecho procesal constitucional puede describirse "como la disciplina jurídica, situada dentro del campo del derecho procesal, que se ocupa del estudio sistemático de las instituciones y de los órganos por medio de los cuales pueden resolverse los conflictos relativos a la aplicación de los principios, valores y disposiciones fundamentales, con el objeto de reparar la violación de los mismos. [... Esta rama del derecho procesal general tiene como contenido el análisis de las tres categorías que integran lo que se ha calificado como 'trilogía estructural del proceso', es decir, la acción, la jurisdicción y el proceso. Pero estas tres categorías esenciales poseen aspectos peculiares en el derecho procesal constitucional, y con este motivo, como un ensayo de sistematización de la materia de esta disciplina reciente, todavía en formación, adoptamos la terminología, ya acreditada, del notable procesalista italiano M auro Cappelletti, quien además ha sido uno de los juristas que mayores aportaciones han hecho a este sector del derecho procesal". ${ }^{16}$

\section{LA CONCEPCIÓN DEL DERECHO PROCESAL CONSTITUCIONAL Y SU NATURALEZA JURÍDICA}

En materia de la naturaleza jurídica del derecho procesal constitucional hay tres enfoques: uno que lo hace depender del derecho constitucional, otro del derecho procesal y un tercero que plantea la naturaleza híbrida o mixta de la disciplina. La perspectiva y enfoque que se asume en esta materia, genera consecuencias inevitables en la determinación del contenido de la disciplina del derecho procesal constitucional.

\subsection{El derecho procesal constitucional como parte del derecho constitucional}

Esta perspectiva es asumida en Alemania, por Peter Häberle, el cual considera al derecho procesal constitucional como un derecho constitucional sustantivo y concretizado. Así lo explicita desde 1973 en Alemania, como él mismo lo señala, donde sostiene la peculiaridad del derecho procesal constitucional, el cual lo considera emancipado del resto del derecho procesal, rechazando la doctrina de las lagunas según la cual debe aplicarse supletoriamente las normas procesales civiles. ${ }^{17} \mathrm{El}$ autor sostiene una interpretación que denomina "específicamente jurídico-constitucional, donde hay que elaborar las normas de la Ley del Tribunal Constitucional Federal y los principios del Derecho procesal constitucional". ${ }^{18}$

\footnotetext{
16 FIX-Zamudio, Héctor. (2003). "Breves reflexiones sobre el concepto y contenido del derecho procesal constitucional", en FERRER M AC-GREGOR, Eduardo. Derecho procesal constitucional. Tomo I. Tercera edición (M éxico, D.F. Ed. Porrúa), p. 197.

17 HäberLe, Peter (2005). El Tribunal Constitucional como Tribunal Ciudadano. El recurso constitucional de amparo. Ed. FUNDAp, México, pp. 78-79.

18 HäBERLE, Peter (2005), ob. cit., p. 79.
} 
Häberle considera que "la Conexión funcional del Derecho procesal constitucional formal y el derecho constitucional sustantivo es también consecuencia de la circunstancia de que el Tribunal Constitucional Federal tiene el doble carácter de Tribunal y 'órgano constitucional'. La interpretación y concretización de la Constitución en los procesos especiales del Derecho procesal constitucional es parte de la Constitución como proceso público, lo que plantea exigencias específicas de racionalidad y aceptación. En los códigos procesales comunes, pueden descubrirse muchos conocimientos jurídicos y valores de experiencia, pero el Tribunal Constitucional Federal puede modificarlos conforme a su estatus y una serie de resoluciones recientes muestran que el Tribunal lucha bastante por 'lo específico' del Derecho procesal constitucional (Cfr. BverfGE. 90, 286, 339 y ss.)". ${ }^{19}$

Para César Landa, distinguido constitucionalista y magistrado del Tribunal Constitucional del Perú, del cual fue Presidente, se sitúa en la doctrina peruana en la tesis de Peter Häberle que considera al derecho procesal constitucional como parte del derecho constitucional, como un "derecho constitucional concretizado". A sí Landa sostendrá que "la judicatura constitucional debe contar no solo con instancias y procedimientos propios, sino que requiere de principios y reglas autónomos que configuren un Derecho procesal constitucional, entendido como derecho constitucional concretizado, lo que implica necesariamente tomar una cierta distancia con respecto a las demás normas procesales (P. Häberle). Pero no se trata sólo de aplicar la Constitución en función de normas procedimentales, sino también de darles a dichas normas un contenido conforme a la Constitución, en el marco de una teoría constitucional que le otorgue sentido a la justicia constitucional". ${ }^{20}$

César Landa precisará que "la autonomía procesal no es un dogma, sino un medio para la realización de la Constitución y para que el Tribunal Constitucional no acabe sumergido en la sobrecarga procesal, sino que se convierta en una magistratura garante de la libertad. Por ello, el Derecho procesal constitucional también requiere partir y remitirse a principios generales del derecho procesal, pero que no sean contradictorios con la justicia constitucional, sino que se desprendan de la Constitución". ${ }^{21}$

Por ello, el autor considerado precisará que, "El derecho procesal constitucional debe forjarse en concordancia con los aportes de la teoría constitucional, en materia de derechos fundamentales e interpretación constitucional; por cuanto sólo a partir de la praxis del estado constitucional y del desarrollo de dichos derechos y su interpretación, la teoría constitucional se convertirá en un factor principal de reflexión y de movilización del Derecho procesal constitucional". 22

HÄBERLE, Peter. (2005), Ibíd., pp. 79-80.

20 LANDA, César. (2004). Teoría del derecho procesal constitucional (Lima, Ed. Palestra), p. 13.

21 LANDA, César. (2004). Ob. cit., p. 13.

22 LANDA, César. (2004). Ibíd., p. 13. 
En esta perspectiva, se encuentra también en España, José Julio Fernández Rodríguez, para quien el derecho procesal constitucional se refiere al sector del ordenamiento jurídico que "regula los procesos constitucionales", tratándose de una disciplina preferentemente adjetiva, en las cuales no entran las cuestiones sustantivas y orgánicas. El derecho procesal constitucional se integra en la [... ] "justicia o jurisdicción constitucional, materia que, a su vez, conforma un sector del derecho constitucional". ${ }^{23}$ "Las especificidades propias de la justicia constitucional son de tal importancia que le otorgan unos presupuestos metodológicos y epistemológicos propios al Derecho Procesal Constitucional. [... ]. En todas estas cuestiones, señala el autor, hay que usar una óptica interpretativa específica del Derecho Constitucional al margen del Derecho Procesal general". ${ }^{24}$

\subsection{El derecho procesal constitucional se ubica dentro de la disciplina y ciencia del derecho procesal, aun cuando con especificaciones propias, diferentes del derecho procesal civil, penal o laboral}

En esta perspectiva se sitúa el maestro Fix Zamudio, para el cual el ámbito del derecho procesal constitucional se reduce estrictamente a las garantías constitucionales en un sentido moderno dejando fuera el derecho constitucional procesal.

Héctor Fix Zamudio sitúa al derecho procesal constitucional dentro del derecho procesal, ocupándose éste del "estudio sistemático de las instituciones, los procesos y de los órganos por medio de los cuales pueden resolverse los conflictos relativos a los principios, valores y disposiciones fundamentales, con objeto de reparar las violaciones a los mismos", ${ }^{25}$ aun cuando reconoce que "Es una materia que se encuentra en la confluencia [... ] de los derechos procesal y constitucional, y por ello requiere el apoyo conjunto y constante de los cultivadores de ambas disciplinas". ${ }^{26}$

Fix Zamudio, asumiendo la perspectiva desarrollada por Couture, precisa, a su vez, los límites del derecho procesal constitucional del derecho constitucional procesal, especificando el contenido de este último, el cual estaría integrado por la jurisdicción en sentido constitucional, vale decir, "La función pública que tiene por objeto resolver las controversias jurídicas que se plantean entre dos partes contrapuestas y que deben someterse al conocimiento de un órgano del Estado, el cual decide dichas controver-

\footnotetext{
23 Fernández Rodriguez, José Julio (2006). En respuesta a encuesta en García Belaúnde, Domingo y Espinosa-Saldaña Barrera, Eloy (Coords.) Encuesta sobre Derecho Procesal Constitucional (México, D.F., Ed. Porrua, e Instituto Mexicano de Derecho Procesal Constitucional), p. 62.

24 Fernández Rodríuez, José Julio (2006), p. 62.

25 Fix Zamudio, Héctor (2006). En respuesta a encuesta en García Belaúnde, Domingo y Espinosa-Saldaña Barrera, Eloy (Coords.) Encuesta sobre Derecho Procesal Constitucional, Ed. Porrúa, e Instituto M exicano de Derecho Procesal Constitucional, México, p. 80.

26 Fix ZAmUdio, Héctor (2006), p. 80.
} 
sias de manera imperativa y desde una posición imparcial";27 las garantías judiciales concebidas como el "conjunto de instrumentos establecidos por las normas constitucionales con el objeto de lograr la independencia e imparcialidad del juzgador"; y las garantías de las partes, las que poseen los justiciables cuando acuden a solicitar la prestación jurisdiccional.

En la misma perspectiva se sitúa su discípulo, Eduardo Ferrer Mac-Gregor, quien conceptualiza el derecho procesal constitucional como una disciplina "que se encarga del estudio sistemático de la jurisdicción, órganos y garantías constitucionales, entendiendo estas últimas como los instrumentos predominantemente de carácter procesal dirigidos a la protección y defensa de los valores, principios y normas de carácter constitucional". 28

Para José Ovalle Favela el derecho procesal constitucional es “Una disciplina que tiene por objeto el estudio del conjunto de normas que regulan el proceso destinado a solucionar los conflictos sobre la interpretación y aplicación de las normas constitucionales". ${ }^{29}$

En la misma perspectiva se sitúan, entre otros, Jesús González Pérez, Domingo García Belaúnde, Juan Colombo Campbell, Andrés Bordalí Salamanca.

Para González Pérez el derecho procesal constitucional es derecho procesal si “tiene por objeto el estudio de la reglamentación de los procesos constitucionales y no va más allá, extendiéndose al estudio de las cuestiones de fondo que en ellos se debaten. [... ]. Si, por razones prácticas, quiere hacerse otra cosa y abordar cuestiones materiales relacionadas con la defensa de la Constitución, estaríamos ante un objeto híbrido que ya solo podría tratarse correctamente utilizando las técnicas de las respectivas ciencias". ${ }^{30}$

Para González Pérez el derecho procesal constitucional se ocupa del conjunto normativo que regula el Tribunal Constitucional y los procesos que él conoce, siendo una rama netamente procesal.

González Pérez define el derecho procesal constitucional como "el conjunto de normas que regulan el proceso constitucional" o "El conjunto de normas que regulan los requisitos, el procedimiento y los efectos del proceso constitucional". ${ }^{31}$

27 Fix-Zamudio, Héctor (2003). Derecho constitucional mexicano y comparado (M éxico, D.F.), p. 220.

28 Ferrer Mac Gregor, Eduardo (2006). En respuesta a encuesta en García Belaúnde, Domingo y EspinosaSaldaña Barrera, Eloy (Coords.) Encuesta sobre Derecho Procesal Constitucional (M éxico, D.F., Ed. Porúa, e Instituto M exicano de Derecho Procesal Constitucional), p. 83.

29 Ovalle FAVela, Jorge (2006). En respuesta a encuesta en García Belaúnde, Domingo y Espinosa-Saldaña Barrera, Eloy (Coords.) Encuesta sobre Derecho Procesal Constitucional (M éxico, D.F. Ed. Porrúa e Instituto Mexicano de Derecho Procesal Constitucional), p. 86.

30 González Pérez, Jesús (2006). En respuesta a encuesta en García Belaúnde, Domingo y Espinosa-Saldaña Barrera, Eloy (Coords.) Encuesta sobre Derecho Procesal Constitucional (M éxico, D.F. Ed. Porrúa, e Instituto Mexicano de Derecho Procesal Constitucional), pp. 65-66.

31 González Pérez, Jesús (2006), p. 65. 
García Belaúnde sostiene que la jurisdicción constitucional debe culminar en un derecho procesal constitucional, siendo una rama del derecho procesal, no siendo plenamente autónoma. "El derecho procesal constitucional arrastra una serie de conceptos de derecho procesal (o teoría del proceso, como también se estila) de la que es deudor y de los que se sirve. Pero a su vez, tiene otros que le son propios y que le vienen de su peculiar naturaleza, que es servir de instrumento de realización del Derecho Constitucional". ${ }^{32}$ El autor se encarga de explicitar que para "utilizar el Derecho Procesal Constitucional, hay que saber Derecho Constitucional, lo cual, lamentablemente, no siempre ocurre". ${ }^{33}$

Para Juan Colombo Campbell, el derecho procesal constitucional es "aquella rama del derecho público que establece las normas procesales orgánicas y funcionales necesarias para dar eficacia real a la normativa constitucional, cuando surja un conflicto entre un acto de autoridad o de un particular y sus disposiciones, agregando que le corresponde la función de aportar al sistema jurídico nacional los elementos orgánicos y funcionales necesarios y apropiados para que un conflicto constitucional pueda ser determinado por medio de una decisión jurisdiccional, logrando así la plena vigencia de la supremacía constitucional". ${ }^{34}$

Colombo Campbell se sitúa también en una perspectiva procesal, señalando que “El Derecho Procesal Constitucional es aquella rama del derecho público que establece las normas procesales orgánicas y funcionales necesarias para dar eficacia real a la normativa constitucional, cuando surja un conflicto entre un acto de la autoridad o de un particular y sus disposiciones". ${ }^{35}$

Para Bordalí Salamanca, "si se puede hablar en el derecho chileno de una disciplina bajo el rótulo Derecho Procesal Constitucional, es para identificar un área de estudio que, partiendo de la unidad del proceso y utilizando los conceptos y principios fundamentales acuñados por la ciencia procesal, analice el proceso y los procedimientos por medio de los cuales tanto el Tribunal Constitucional como los tribunales ordinarios controlan la supremacía constitucional y la tutela de los derechos fundamentales". ${ }^{36}$

En el mismo sentido se pronuncia Salvador Enrique Anaya, para el cual el derecho procesal constitucional constituye “La existencia de un sistema (o más propiamente, un

32 García Belaúnde, Domingo (2008). El derecho procesal constitucional en perspectiva (M éxico, D.F. Ed. Porrúa), p. 99.

33 García Belaúnde, Domingo (2008). El derecho procesal constitucional en perspectiva (M éxico, D.F. Ed. Porrúa), p. 99.

34 Colombo Cam pbell, Juan (2002) en Prólogo fechado en diciembre de 2002 al libro de Bordalí, Andrés, Temas de Derecho procesal constitucional (Santiago, Ed. Fallos del Mes-Universidad Austral de Valdivia), p. 4.

35 Colombo Cam pBell, Juan (2002). "Funciones del derecho procesal constitucional”, en Revista lus et Praxis, año 8, $N^{\circ} 2$, Facultad de Ciencias Jurídicas y Sociales, Universidad de Talca, Talca, Chile, p. 12.

36 Bordali, Andrés (2002). Temas de Derecho procesal constitucional (Santiago, Ed. Fallos del Mes-Universidad Austral de Valdivia), p. 16. 
subsistema) de normas diferenciales del derecho procesal general, destinadas a la aplicación jurisdiccional de la Constitución, no exige ninguna competencia especializada, pero es común circunstancia que cuando se establece un área procesal especializada, determinándose que a ciertas entidades judiciales corresponde, con exclusión de las otras (exclusividad procesal), el conocimiento y decisión sobre determinadas pretensiones, lo que supone la exclusiva tramitación respecto de una clase de procesos; construyéndose así la generalmente denominada jurisdicción constitucional (utilizando el primer vocablo, claro, en la acepción de competencia especializada), de la que el instituto más característico es el control jurisdiccional de la constitucionalidad de las leyes" ${ }^{37}$

Finalmente, Hernández Valle, quien asume que el Derecho Procesal Constitucional, aunque "es sustancialmente procesal", tendrá que reconocer que "hay principios de Derecho Constitucional sustantivo que le son aplicables y que la convierten en una rama procesal muy particular, con principios inclusive contrarios a los de la dogmática procesalista". ${ }^{38}$

\subsection{El derecho procesal constitucional como una mixtura o hibridación de derecho constitucional y derecho procesal}

En esta perspectiva mixta, podemos situar a Zagrebelsky, quien señala que la jurisdicción constitucional y los procedimientos de aplicación de la Constitución para la resolución de casos controvertidos lleva aparejada una teoría de la Constitución como norma sustancial, cada concepción de la Constitución lleva aparejado una concretización del procedimiento, así como cada concepción del procedimiento lleva aparejada una concepción de la Constitución. ${ }^{39}$

Zagrebelsky afirma que esta "interdependencia recíproca es materia de muchas posibles reflexiones que llevarían lejos y sobre cuestiones decisivas. Por ahora me limito a hacer la afirmación, una afirmación que -para la justicia constitucional- me parece a primera vista más capaz de ser comprendida que todas las otras que se debatieron en el ámbito de la reflexión procesalista general: la pura y simple dependencia -instrumentalidad de las reglas procedimentales respecto de las normas sustanciales; la dependencia, al contrario, del derecho sustancial respecto al derecho procedimental- hasta la

37 Anaya, Salvador Enrique (2004). "A plicación de la Constitución y Derecho Procesal Constitucional", en Castañeda Otsu, Susana Ynés (Coord.) Derecho procesal constitucional, Tomo I, Segunda edición (Lima, Jurista Editores), pp. 146 y ss. Citado también por Rodríguez Domínguez, Elvito (2006). Manual de Derecho procesal constitucional. Tercera edición (Lima, Ed. Grijley), p. 77.

38 HeRnández Valle, en respuesta a encuesta en García Belaúnde, Domingo y Espinosa-Saldaña Barrera, Eloy (Coords.) 2006. Encuesta sobre Derecho Procesal Constitucional (México, Ed. Porrúa e Instituto Mexicano de Derecho Procesal Constitucional), p. 51.

39 Zagrebelsky, Gustavo (2004). ¿Derecho Procesal Constitucional? y otros ensayos de justicia constitucional (México, D.F. Ed. FUNDAp), pp. 17-18. 
inexistencia del primero, sino como producto de actividad procesal- o su recíproca independencia, como pertenecientes a dos ámbitos conceptuales separados". ${ }^{40}$ Zagrebelsky termina sus reflexiones en este artículo sobre ¿Derecho procesal constitucional?, afirmando, "un derecho procesal constitucional, sí, pero "sui generis" -es más: muy "sui generis"-, que comprenda en sí pluralidad de perspectivas, que deben reconstruirse alrededor de bienes jurídicos múltiples. El derecho procesal capaz de comprender las razones no siempre coincidentes de la tutela subjetiva de los derechos fundamentales, pero también las razones de la tutela objetiva de la Constitución". ${ }^{41}$

Néstor Pedro Sagüés, afirma en su ya clásico Derecho Procesal Constitucional, Tomo I, que el derecho procesal constitucional tiene "un rol instrumental, en el sentido que le toca tutelar la vigencia y operatividad de la Constitución, mediante la implementación de la judicatura y de los remedios procesales pertinentes", 42 "si un proceso está expresa o implícitamente tratado en la Constitución, habrá desde luego que desenvolverlo procesalmente conforme a la estructura normativa axiológica e ideológica que marque la Constitución. Y si se trata de un proceso destinado a proteger la supremacía de la Constitución, sin haber sido creado por ella (esto es, si ha tenido exclusivamente su origen en el legislador ordinario), eso no exime al procesalista constitucional de pensar a dicho trámite y a hacerlo funcionar según y en razón de su objeto específico, que es la Constitución". ${ }^{43} \mathrm{El}$ autor agrega "Lo dicho no debe llevar a asombro: muestra que, para numerosas figuras jurídicas, es necesario el aporte conjunto de procesalistas y constitucionalistas". ${ }^{44}$

M aría Mercedes Serra Rad, discípula de Néstor Sagüés, define el derecho procesal constitucional como la "disciplina jurídica integrada por las normas, principios, comportamientos sociales y valores jurídico-políticos, que instrumentan jurisdiccionalmente la supremacía constitucional, a través de la regulación de los requisitos, contenidos y efectos de los procesos constitucionales y de la magistratura constitucional". ${ }^{45}$ La autora considera al derecho procesal constitucional como una disciplina situada en una posición ecléctica, ubicando a la disciplina "como un sector que interesa a ambas ramas" ${ }^{46}$ el derecho constitucional y el derecho procesal. En definitiva, señala la auto$\mathrm{ra}$, "El derecho procesal constitucional aparece como un sector del mundo del derecho que atañe tanto al derecho constitucional como al derecho procesal, siendo objeto de estudios de ambas ciencias y recibiendo influjos recíprocos". ${ }^{47}$

\footnotetext{
40 Zagrebelsky, Gustavo (2004). ¿Derecho Procesal Constitucional? y otros ensayos de justicia constitucional (México, D.F. Ed. FUNDAp), pp. 18-19.

41 ZAGReBeLSKY, Gustavo (2004), p. 57.

42 SAgÜÉs, Néstor Pedro (1989). Derecho procesal Constitucional. Tomo I: Recurso extraordinario. Segunda edición actualizada y ampliada. Ed. Astrea, p. 4.

43 SAGÜÉs, Néstor Pedro (1989), p. 6.

44 SAGÜÉS, Néstor Pedro (1989), p. 5.

45 SerRa Rad, M aría Mercedes (1992). Procesos y recursos constitucionales (Buenos Aires, Ed. Depalma), p. 38.

46 SeRra Rad, María Mercedes (1992), p. 47.

47 SerRa Rad, María Mercedes (1992), p. 47.
} 
José Antonio Rivera Santiváñez conceptualiza el derecho procesal constitucional como una "disciplina del derecho público que estudia el conjunto de normas y reglas que definen el sistema de control de constitucionalidad, la organización y el funcionamiento de los organismos que ejercen la jurisdicción constitucional, así como la configuración procesal de los procesos constitucionales a través de los cuales se ejerce el control de constitucionalidad de un determinado Estado". ${ }^{48}$ Ya antes, en su libro Jurisdicción constitucional. Procesos constitucionales en Bolivia, había explicitado que el derecho procesal constitucional "estudia los principios, normas y reglas que regulan la organización y funcionamiento del sistema de control de constitucionalidad, definiendo el o los órganos encargados de dicha labor, su estructura orgánica, los mecanismos o institutos a través de los cuales se ejerce el control, así como los procedimientos jurisdiccionales establecidos para el efecto"..$^{49}$ Es una disciplina mixta por cuanto "en su objeto de estudio comprende tanto la parte orgánica, respecto a la organización y funcionamiento de los órganos encargados del control de constitucionalidad, cuanto de la parte procesal respecto de los procesos constitucionales y su configuración procesal". ${ }^{50}$

Para Pablo Luis Manili, el derecho procesal constitucional excede el derecho procesal, ya que considera "imposible escindir la acción del derecho tutelado, a menos que pensemos que todos los procesos constitucionales son variantes del amparo, lo cual es inconcebible por razones históricas y técnicas. Acción y derecho, derecho y acción, son las dos caras de una misma moneda y se influyen mutuamente; sostener que el derecho procesal constitucional es meramente procesal implica negar esa interacción. Incluso, obsérvese que aquellos que consideran al Derecho Procesal Constitucional como parte del procesal, incluyen dentro de él a una serie de institutos que creemos son propios del Derecho Constitucional". ${ }^{51}$ El autor considera la autonomía de la disciplina como su estudio y análisis científico en un modulo separado del derecho constitucional y del derecho procesal.

Para Francisco Zúñiga Urbina el derecho procesal constitucional es "primordialmente, una mixtura, con un predominio del derecho adjetivo, ya que sus ejes temáticos: acciones-procesos constitucionales y judicatura constitucional, son propios del derecho procesal. Con todo, el derecho material de la judicatura constitucional es el Derecho Constitucional, básicamente el derecho subjetivo público de la Constitución, que se actualiza a situaciones y conflictos mediante la sentencia. Ello sitúa a la hermenéutica

48 Rivera Santivá ÑEZ, José A ntonio (2006). En respuesta a encuesta en García Belaúnde, Domingo y Espinosa-Saldaña Barrera, Eloy (Coords.) Encuesta sobre Derecho Procesal Constitucional (M éxico, D.F. Ed. Porrúa, e Instituto Mexicano de Derecho Procesal Constitucional), p. 32

49 Rivera Santiváñez, José A ntonio (2004). Jurisdicción constitucional. Procesos constitucionales en Bolivia. Segunda edición actualizada (Cochabamba, Ed. Kipus), p. 8.

50 Rivera Santiváñez, José Antonio (2006), p. 33.

51 ManiLI, Pablo Luis (2005). "Perfil del derecho procesal constitucional", en Palominos Manchego, José (Coord.). El Derecho Procesal Constitucional Peruano. Estudios en Homenaje a Domingo García Belaúnde. Tomo I (Lima, Ed. Jurídica Grijley), p. 153. 
constitucional en el centro de gravedad del Derecho Constitucional contemporáneo y permite hacer puente con diversas disciplinas jurídicas tradicionales y modernas". ${ }^{52}$

En el proceso constitucional hace a la esencia de su función, controlar la constitucionalidad y legalidad de los actos de autoridades y particulares, de forma que la interpretación de los hechos y del derecho no pueden tener el condicionamiento de lo alegado por las partes, siendo necesario ver las consecuencias, efectos y circunstancias que tiene el caso concreto frente a toda la sociedad. ${ }^{53}$

En Brasil, Ivo Dantas precisa su posición en la materia señalando que "a nosotros nos parece que ambas disciplinas -el Derecho Procesal Constitucional y el Derecho Constitucional Procesal- pertenecen mucho más al Derecho Constitucional que al Derecho Procesal, aunque es evidente que se valga de conceptos y normas de la Ley Procesal" ${ }^{54} \mathrm{El}$ autor agrega que "ante esta situación, que lo mejor es decir que se trata de una posición límite entre el Derecho Constitucional y el proceso". ${ }^{55}$

En Uruguay, Eduardo Esteva Gallicchio considera que el Derecho Procesal Constitucional precisa que "tiene por objeto sistematizar el estudio de los instrumentos procesales dirigidos a la resolución de las controversias derivadas de la aplicación de las disposiciones constitucionales", ${ }^{56}$ precisando que en su opinión, "el Derecho procesal Constitucional debe ser considerado una disciplina jurídica autónoma. Comencé considerándola una disciplina procesal, pero actualmente estimo que es una disciplina mixta". ${ }^{57}$

Por nuestra parte, consideramos que el derecho procesal constitucional es una rama del derecho público que estudia el conjunto de principios y normas constitucionales y legales que definen y configuran el sistema de defensa de la Constitución y de protección de los derechos fundamentales y su respectiva interpretación, como asimismo el sistema de control de constitucionalidad, la organización y funcionamiento de los órganos que ejercen dicha función jurisdiccional, la configuración de los procesos y procedimientos constitucionales, las resoluciones emitidas por las magistraturas constitucionales y los tipos y efectos de las respectivas sentencias, como asimismo las reglas y postulados de interpretación constitucional utilizados por tales jurisdicciones.

52 ZúÑIGA URBInA, Francisco (2006). En respuesta a encuesta en García Belaúnde, Domingo y EspinosaSaldaña Barrera, Eloy (Coords.) Encuesta sobre Derecho Procesal Constitucional (México, D.F. Ed. Porúa e Instituto Mexicano de Derecho Procesal Constitucional), p. 58.

53 Gozainı, Osvaldo (2006). En respuesta a encuesta en García Belaúnde, Domingo y Espinosa-Saldaña Barrera, Eloy (Coords.) Encuesta sobre Derecho Procesal Constitucional (M éxico, D.F. Ed. Porrúa e Instituto Mexicano de Derecho Procesal Constitucional), p. 24.

54 DANTAS, Ivo (2006). En respuesta a encuesta en García Belaúnde, Domingo y Espinosa-Saldaña Barrera, Eloy (Coords.). Encuesta sobre Derecho Procesal Constitucional (México, D.F. Ed. Porrúa e Instituto Mexicano de Derecho Procesal Constitucional), p. 39.

55 DANTAS, Ivo (2006), p. 40.

56 Esteva Gallicchio, Eduardo (1984). Lecciones de introducción al derecho constitucional, Tomo I, M ontevideo, p. 10.

57 Esteva Gallicchio, Eduardo (2006). En respuesta a encuesta en García Belaúnde, Domingo y EspinosaSaldaña Barrera, Eloy (Coords.). Encuesta sobre Derecho Procesal Constitucional (M éxico, D.F, Ed. Porúa e Instituto Mexicano de Derecho Procesal Constitucional), p. 109. 
El derecho procesal constitucional implica la existencia de determinadas instituciones, valores, principios, derechos y garantías constitucionales que se operacionalizan litigiosamente en procesos y procedimientos que regula la disciplina, los cuales implican la confluencia aplicativa de principios e instituciones tanto de derecho constitucional como de derecho procesal con particularidades propias de los procesos constitucionales. Es una disciplina sustantiva en la medida que tiene por objeto de estudio la defensa de la Constitución y la interpretación de la Carta Fundamental y los derechos fundamentales por las jurisdicciones constitucionales; estudia los órganos constitucionales, su organización, funciones y atribuciones; y es una disciplina adjetiva en la medida que utiliza principios y reglas procesales, aun cuando con peculiaridades propias de los procesos constitucionales, en especial, la legitimación, partes, concepto de cosa juzgada, relativización principio de congruencia, los tipos de sentencia, la fuerza vinculante de la sentencia constitucional, entre otras materias.

A sí, esta novel disciplina jurídica reconoce elementos y se alimenta de la dogmática constitucional y procesal en una interacción en la cual ninguno de ellos somete 0 anula al otro, reconociendo en la Constitución su derecho sustantivo y en el derecho procesal el derecho adjetivo. Además debe tenerse presente que el objeto que está en litigio es estrictamente una materia constitucional (la defensa y garantía de los derechos fundamentales y el control del poder político en el Estado Constitucional democrático haciendo efectiva la supremacía constitucional).

\section{EL DERECHO PROCESAL CONSTITUCIONAL Y SU OBJETO DE ESTUDIO}

Durante las últimas dos décadas del siglo XX y esta primera década del siglo XXI, puede sostenerse que se ha desarrollado y expandido el interés académico por el derecho procesal constitucional, como asimismo se ha avanzado en la delimitación, vale decir, en la fijación del contenido y fronteras de esta nueva disciplina del derecho público, aún en desarrollo.

\subsection{Tesis que sostiene como objeto del derecho procesal constitucional la magistratura y los procesos constitucionales}

Esta posición es desarrollada por Néstor Sagüés, quien sostiene la existencia de una versión mínima del derecho procesal constitucional, que lo entiende como una disciplina de carácter procesal y que tiene como temas centrales la magistratura constitucional y los procesos constitucionales, pudiendo sintetizarse en la jurisdicción constitucional. Así el derecho procesal o constitucional se ocuparía de los órganos y de los procesos que custodian la supremacía de la Constitución. ${ }^{58}$ Para Sagüés, el contenido

58 SAGÜÉs, Néstor Pedro (2006). Derecho procesal constitucional. Logros y obstáculos. Ed. Ad-Hoc y Konrad Adenauer Stifftung, Buenos Aires, p. 21. 
básico del derecho procesal constitucional sería la jurisdicción constitucional "comprensiva de la magistratura constitucional, u órgano de aquella, y los procesos constitucionales, que son los instrumentos destinados a asegurar la supremacía constitucional". ${ }^{59}$ Sagüés señala que ha adherido a la tesis restrictiva del derecho procesal constitucional, aunque reconoce que numerosos programas de la asignatura se sitúan en una concepción amplia, y que el punto no está aún resuelto. ${ }^{60}$

Sagüés explicita que el derecho procesal constitucional presenta también un desafío metodológico que se requiere enfrentar con un enfoque tridimensional, desde la perspectiva normativa, de la realidad y de los valores. ${ }^{61}$

Desde la perspectiva normativa, puede constatarse que, además del derecho legislado o positivo, a menudo las jurisdicciones constitucionales se enfrentan, por diversas razones, con prácticas desarrolladas pretorianamente o desarrollo de un derecho consuetudinario procesal constitucional, producto entre otras razones de vacíos normativos, por la falta oportuna de dictación de normas sustantivas o adjetivas; o por la dictación de sentencias que determinan la inconstitucionalidad de normas infraconstitucionales, emergiendo como bien señala Sagüés, un derecho procesal constitucional informal o consuetudinario que va configurando el ejercicio práctico de la jurisdicción constitucional de cada país, por lo que el derecho procesal constitucional requiere poner atención a los usos y costumbres no positivados.

Por otra parte, el derecho procesal constitucional se enfrenta al desafío de la regulación sistemática, bajo principios comunes, de los procesos constitucionales (entre otros, Costa Rica, Perú), mientras en otros se realizan esfuerzos y se estructuran proyectos de codificación total o parcial en la materia.

También debe tenerse presente en el estudio del derecho procesal constitucional, la dimensión fáctica, que vuelve el análisis a las actitudes y conductas de los magistrados constitucionales, ya que el éxito de una magistratura constitucional está en su independencia e imparcialidad, lo que permite mirar con preocupación no solo la conformación de magistraturas constitucionales serviles a los gobiernos de turno, como ocurre de manera ejemplar hoy con la Sala Constitucional del Tribunal Supremo de Venezuela, ${ }^{62}$ como también la eventual conformación de jurisdicciones constitucionales orientadas a un rol determinado de oposición y obstaculización del respectivo gobierno del país, cualquiera sea su programa gubernativo. Lo que exige verificar los resguardos institucionales para el logro de una jurisdicción constitucional conforme

59 SAgüÉs, Néstor Pedro (1989). Derecho procesal constitucional. Recurso extraordinario (Buenos Aires, Ed. Astrea), p. 10.

60 SAgüÉs, Néstor Pedro (2006). Derecho procesal constitucional. Logros y obstáculos (Buenos Aires, Ed. Ad-Hoc y Konrad Adenauer Stifftung), p. 23.

61 SAgüÉs, Néstor Pedro (2006). Derecho procesal constitucional. Logros y obstáculos (Buenos Aires, Ed. Ad-Hoc y Konrad Adenauer Stifftung), p. 24.

62 Ver, Brewer Carías, Allan R. (2007). Crónica sobre la 'in'justica Constitucional. La Sala Constitucional y el autoritarismo en Venezuela (Caracas, Ed. Jurídica Venezolana). 
con un Estado constitucional democrático. Por tanto, el derecho procesal constitucional debe analizar críticamente las conductas de las jurisdicciones constitucionales y sus normativas reguladoras, como asimismo debe realizar un esfuerzo de convencimiento de la necesidad de transparencia y de consideración de adecuadas competencias y honestidad de los candidatos por parte de los órganos encargados de realizar los nombramientos de los magistrados constitucionales.

En este ámbito es necesario analizar los paradigmas mentales, la flexibilidad o rigidez para afrontar nuevas realidades jurídicas.

Desde el enfoque valorativo, el derecho procesal constitucional debe analizar los eventuales paradigmas mentales y prejuicios de los magistrados constitucionales para considerar determinadas fuentes del derecho constitucional y de los derechos fundamentales, considerar las diversas concepciones sobre la Constitución que tienen los magistrados constitucionales, sus concepciones sobre jerarquización o ponderación de las situaciones en que se aplican los derechos fundamentales, junto a diversos otros factores, los enfoques interpretativos creativos o estáticos, para solo señalar algunos aspectos que irán determinando las decisiones jurisdiccionales constitucionales y fijarán las líneas jurisprudenciales de dichas magistraturas constitucionales en un momento histórico determinado, como sus eventuales modificaciones con otra conformación o integración de la magistratura constitucional.

\subsection{La tesis intermedia de derecho procesal constitucional}

Para García Belaúnde el contenido de la disciplina derecho procesal constitucional está constituido básicamente por la jurisdicción constitucional, los procesos constitucionales y la magistratura constitucional, ${ }^{63}$ sin perjuicio de distinguir entre un derecho procesal constitucional general y un derecho procesal constitucional particular, que es la disciplina desarrollada en torno a un país determinado.

El autor analizado considera que el desarrollo del derecho procesal constitucional se inicia con una parte general del derecho procesal constitucional tiene que considerar la jurisdicción constitucional y los diversos modelos que se hayan desarrollado en la materia, la existencia de magistratura constitucional especializada y la existencia de diversos procesos constitucionales, además de tratar el derecho procesal constitucional como disciplina relativamente autónoma. ${ }^{64}$

En una perspectiva similar se sitúa Juan Colombo Campbell en Chile, el cual señala que el Derecho Procesal Constitucional comprende el desarrollo de las siguientes áreas

63 García Belaúnde, Domingo (2003). De la jurisdicción constitucional al Derecho Procesal Constitucional. Cuarta edición corregida y aumentada (Lima, Ed. Grijley), p. 60.

64 García Belaúnde, Domingo (2008). El derecho procesal constitucional en perspectiva. México, D.F. Ed. Porrúa, p. 102. 
temáticas: "a) el conflicto constitucional y sus formas de solución, b) El Derecho Procesal Constitucional orgánico, y c) El Derecho Procesal Constitucional funcional"; 65 más adelante el autor determina como tareas del Derecho Procesal Constitucional, "a) Velar por la aplicación del principio de la supremacía constitucional y de la eficacia de las garantías personales, b) Solucionar los conflictos constitucionales, c) Realizar la labor integ radora de la justicia constitucional, d) La defensa de la Constitución a través de su labor de intérprete de la Constitución, y e) Colocar a disposición del Estado los elementos técnicos adecuados para que opere la Carta Fundamental". 66

Domingo García Belaúnde propone un Syllabus ${ }^{67}$ que contendría como primer ámbito la: Jurisdicción constitucional que es considerada en sentido estricto, o sea como la capacidad de "decir" el derecho en materia constitucional. En este apartado deben verse los siguientes temas: El valor jurídico de la Constitución. El control y sus alcances. Sistemas de control, la sentencia constitucional y la interpretación constitucional, teniendo presente que el supremo intérprete de la Constitución son los tribunales constitucionales y el desarrollo de los postulados de interpretación constitucional. Un segundo ámbito de estudio son los procesos constitucionales, aquí se distingue entre proceso en sentido estricto, los que nacen de la Constitución en forma expresa, para cautelar valores o principios constitucionales, como son los procesos de habeas corpus y amparo. El tercer ámbito está conformado por el estudio de la magistratura constitucional, donde se examina si ella es especializada, si ella es autónoma, si ella se encuentra dentro o fuera del poder judicial, sus competencias y sus decisiones jurisdiccionales. Luego, debe considerarse la parte positiva del derecho procesal constitucional que estudia la realidad de cada país en la materia, el derecho procesal constitucional argentino, el peruano o el chileno. Debiendo tenerse presente la realidad de los estados federales, donde puede desarrollarse y de hecho así se hace, un derecho procesal constitucional local, como ocurre en Argentina o en México, siendo este derecho local tributario del derecho procesal constitucional nacional. ${ }^{68}$

Domingo García sostiene que la jurisdicción constitucional transnacional no corresponde considerarlo como parte del derecho procesal constitucional, el cual es un derecho estatal y no internacional, aunque vinculada con este último ámbito.

A su vez, García Belaúnde en relación al planteamiento de Couture y Fix Zamudio de la existencia de un Derecho Constitucional Procesal, cuestionará la existencia de este, en la medida de que las disciplinas jurídicas tienen un aspecto constitucionalizado para dotar de mayor solidez a sus enunciados, pero ello no autoriza a crear una

65 Colombo Campbelt, Juan (2002). "Las funciones del derecho procesal constitucional”, en Revista lus et Praxis, año $8 \mathrm{~N}^{\circ} 2$ (Talca, Facultad de Ciencias Jurídicas y Sociales, Universidad de Talca), p. 13.

66 Colombo Campbell, Juan (2002), p. 30.

67 Garcia Belaúnde, Domingo (2003). De la jurisdicción constitucional al Derecho Procesal Constitucional. Cuarta edición, corregida y aumentada (Lima, Ed. Grijley), pp. 60-68.

68 García Belaúnde, Domingo (2008). El derecho procesal constitucional en perspectiva (M éxico, Ed. Porrúa), p. 102. 
disciplina jurídica de cada uno de ellos ya que duplicarían las disciplinas existentes, debiendo tener en consideración que la jurisdicción es parte sustancial del derecho constitucional, como las garantías judiciales y las garantías de las partes relacionadas con los derechos fundamentales.

\subsection{La posición amplia sobre el derecho procesal constitucional}

En esta posición encontramos el análisis de Héctor Fix Zamudio, el cual considera que el derecho procesal constitucional tiene por objeto "los instrumentos predominantemente procesales que están dirigidos a la reintegración del orden constitucional cuando el mismo ha sido desconocido o violado por los órganos del poder", 69 está integrado por la jurisdicción constitucional orgánica, que estudia el control constitucional jurisdiccional sobre normas jurídicas infraconstitucionales y los controles sobre contiendas o conflictos de competencias horizontales y verticales entre órganos estatales. A simismo, sitúa, siguiendo a Cappelletti, ${ }^{70}$ una jurisdicción constitucional de la libertad que establece las garantías jurisdiccionales destinadas a la protección de los derechos fundamentales, donde se encuentra el habeas corpus, el amparo, el habeas data; y la jurisdicción constitucional supranacional, en la que se analizan las jurisdicciones internacionales protectoras de derechos humanos y las jurisdicciones supranacionales e internacionales respecto de procesos de integración entre estados.

Eduardo Ferrer Mac-Gregor, discípulo de Fix Zamudio y destacado procesalista de la generación joven de M éxico y uno de los motores de la difusión del derecho procesal constitucional continental, agrega a las tres dimensiones consideradas, en el caso de Estados Federales como México y Argentina, entre otros, un derecho procesal constitucional local, que estudia las instituciones procesales constitucionales provinciales o estaduales.

\subsection{Tesis amplísima del derecho procesal constitucional}

Para Juan Carlos Hitters, destacado magistrado de la Corte Suprema de La Plata y procesalista argentino, "el derecho procesal constitucional regula el proceso constitucional y su objeto lo constituye la materia constitucional. Podemos decir que su contenido apunta a cuatro grandes vertientes: 1) el debido proceso legal, 2) las garantías de las partes, 3) las categorías de la jurisdicción, y 4) las garantías judiciales". ${ }^{71}$ A simismo,

69 Fix ZamUdio, Héctor (2002). Introducción al derecho procesal constitucional (M éxico, D.F. Ed. FUNDAp), pp. 26-27.

70 Ver CapPelletr, M auro (1961). La jurisdicción constitucional de la libertad, México, UNAM y CAPPELletT, Mauro (1984). "Necesidad y legitimidad de la justicia constitucional", en Tribunales Constitucionales Europeos y Derechos Fundamentales (M adrid, Centro de Estudios Constitucionales), pp. 599-662.

71 HITTERS, Juan Carlos. "El Derecho procesal constitucional", en Ferrer Mac-Gregor, Eduardo. Derecho Procesal Constitucional. Tercera edición, Tomo I (M éxico, D.F. Ed. Porrúa), p. 278. 
le reconoce al derecho procesal constitucional "autonomía pedagógica y científica", 72 estableciendo además que "No obstante, hemos tratado de demostrar que pese a estar informada por los genes de aquellas dos grandes disciplinas, su esencia, es netamente procesal, pese a que también reconocimos lo difícil que resulta el encasillamiento, habida cuenta de lo ríspido que es la propia demarcación de los limbos del campo constitucional y los del procesal". ${ }^{73}$

Una perspectiva similar asume Gozaíni, el que sostiene que el derecho procesal constitucional se ocupa de la magistratura constitucional y del sistema procesal específico. ${ }^{74}$ En el ámbito de la magistratura constitucional, se pueden encontrar variantes de control constitucional difuso o concentrado, siendo los puntos de análisis: "1) Los poderes del juez constitucional; 2) la legitimación para actuar; 3 ) los contenidos de la sentencia judicial; 4) los alcances y efectos de la cosa juzgada, entre otros". ${ }^{75} \mathrm{En}$ el ámbito del debido proceso constitucional, deben ser considerados como puntos básicos: “1) el acceso a la justicia; 2) los principios de bilateralidad y de contradicción; 3) la carga de la prueba; 4) la fundamentación de las resoluciones judiciales; 5) la ejecución de la sentencia". ${ }^{76}$

\subsection{Nuestras consideraciones sobre el contenido del derecho procesal constitucional}

Cabe señalar que sobre el contenido del derecho procesal constitucional hay acuerdo sobre los mínimos que esta disciplina debe abordar que son aquellos que sostiene la tesis reducida del derecho procesal constitucional, vale decir, la magistratura y los procesos constitucionales.

Sin embargo, nos parece que un derecho procesal constitucional debe partir con una parte de dogmática general que debe comprender el concepto, naturaleza y contenidos del derecho procesal constitucional, la concepción normativa de la Constitución, los conceptos de justicia y jurisdicción constitucional, los modelos de jurisdicción

72 Himters, Juan Carlos. "El Derecho procesal constitucional", en Ferrer Mac-Gregor, Eduardo. Derecho procesal Constitucional. Tercera edición, Tomo I (M éxico, D.F. Ed. Porrúa), p. 285.

73 HITTERS, Juan Carlos. "El Derecho procesal constitucional", en Ferrer Mac-Gregor, Eduardo. Derecho procesal Constitucional. Tercera edición, Tomo I, Ed. Porrúa, México, p. 285. A simismo en respuesta a encuesta, García Belaúnde, Domingo y Espinosa-Saldaña Barrera, Eloy (Coords.) (2006) Encuesta sobre Derecho Procesal Constitucional, Ed. Porrúa e Instituto M exicano de Derecho Procesal Constitucional, México, pp. 11-12.

74 Gozaínı, Osvaldo (2006). Respuesta en García Belaúnde, Domingo y Espinosa-Saldaña Barrera, Eloy (Coords.) Encuesta sobre Derecho Procesal Constitucional, Ed. Porrúa e Instituto M exicano de Derecho Procesal Constitucional, México, pp. 11-12. Ver del mismo autor (1995). El derecho procesal constitucional y los derechos humanos (M éxico, D.F. UNAM), pp. 77 y ss.

75 Gozainl, Osvaldo (2006). Respuesta en García Belaúnde, Domingo y Espinosa-Saldaña Barrera, Eloy (Coords.), p. 12.

76 Gozaínı, Osvaldo (2006). Respuesta en García Belaúnde, Domingo y Espinosa-Saldaña Barrera, Eloy (Coords.) Encuesta sobre Derecho Procesal Constitucional, p. 12. 
constitucional, el concepto y caracterización de los tribunales constitucionales, los presupuestos de un sistema de control de constitucionalidad, los diversos procesos constitucionales; las sentencias constitucionales, sus efectos y sus clasificaciones, y la interpretación de la Constitución por las magistraturas constitucionales.

En una segunda parte debe analizarse el modelo y características específicas de la - las magistraturas constitucionales nacionales, su estatuto jurídico, sus competencias, como las fuentes formales del derecho que regulan dichos aspectos. A su vez, deben analizarse los diversos procesos y procedimientos constitucionales destinados a la defensa objetiva de la Constitución, como asimismo, las garantías jurisdiccionales de los derechos fundamentales o del bloque constitucional de derechos fundamentales, cuando se integran al derecho constitucional los tratados de derechos humanos en la materia o cuando se considera la existencia de derechos implícitos o se asume la integración a los derechos fundamentales de los atributos de derechos que se consideran que integran tales derechos y sus garantías provenientes del derecho internacional (derecho consuetudinario, derecho convencional o principios de ius cogens).

En esta parte que es de derecho positivo nacional, cabe el análisis de los niveles subnacionales, estaduales o provinciales de los países federales en que existen constituciones y legislaciones locales, como ocurre, entre otros países con Argentina y México, en la materia, como bien ha hecho ver Ferrer Mac-Gregor.

En este ámbito puede también desarrollarse un análisis de derecho comparado o de información comparativa del derecho procesal constitucional, el que puede concretarse en una perspectiva diacrónica, comparando el derecho procesal constitucional de un país en dos momentos históricos diferentes, analizando la evolución del sistema; o un derecho procesal constitucional comparado sincrónico, que posibilita el análisis de los sistemas de derecho procesal constitucional de dos o más países o de diversos niveles estaduales de un determinado país.

Concordamos con quienes sostienen que el derecho procesal constitucional es aquel que se concreta al interior de un Estado determinado, por lo tanto, los procesos y procedimientos ante jurisdicciones internacionales debe ser estudiado y analizado como parte del derecho internacional, el cual tiene varias ramas como el derecho nacional. De esta manera, consideramos que no es parte del derecho procesal constitucional en un sentido estricto, el estudio de las jurisdicciones internacionales o supranacionales en materia de derechos humanos ni en procesos de integración económica o política, ya que ello excede el derecho estatal. Ello no significa desconocer la importancia vital para el derecho contemporáneo y para el desarrollo de los estados el derecho internacional y las jurisdicciones creadas en su ámbito de acción, como asimismo reconocemos la influencia positiva de las jurisdicciones internacionales y supranacionales en las jurisprudencias de las jurisdicciones nacionales, especialmente en materia de estándares mínimos de derechos humanos, como asimismo, la obligatoriedad de los estados de cumplir de buena fe con las decisiones de dichas jurisdicciones e incorporar en sus criterios de decisión la ratio decidendi de los fallos de la Corte Interamericana y otras jurisdicciones internacionales vinculantes. 
Así estimamos que un Syllabus básico de Derecho Procesal Constitucional debiera contener:

\section{Parte general.}

1. El concepto, objeto y ámbito de estudio del derecho procesal constitucional.

2. Concepto y concepción normativa de la Constitución.

3. La defensa de la Constitución y la supremacía constitucional.

4. La distinción entre justicia y jurisdicción constitucional.

5. Presupuestos de un sistema de jurisdicción constitucional.

6 . Los modelos de control de constitucionalidad.

7. Los tipos de magistraturas constitucionales.

8. Las competencias de las magistraturas constitucionales.

a) La jurisdicción constitucional orgánica (control de normas jurídicas y de conflictos o contiendas de competencia).

b) La jurisdicción protectora de derechos fundamentales.

9. Las sentencias constitucionales y su clasificación.

10. La interpretación constitucional y sus postulados.

\section{La magistratura constitucional.}

1. El estatuto jurídico de los jueces constitucionales.

2. Tipo de magistratura (jueces ordinarios, salas especializadas, tribunales constitucionales).

3. Competencias.

4. La sentencia constitucional, sus tipos y efectos.

5. La ejecución de la sentencia.

\section{Los procesos y procedimientos jurisdiccionales constitucionales naciona- les y locales (en los Estados federales).}

1. El Habeas Corpus.

2. Las acciones y procesos de Amparo, Tutela o Protección de Derechos Fundamentales.

3. Habeas Data.

4. Controles preventivos de constitucionalidad de normas en su proceso de generación en los órganos estatales o en proceso de incorporación desde el derecho internacional.

5. Acciones de inaplicabilidad por inconstitucionalidad.

6 . Acciones de inconstitucionalidad.

7. Contiendas o conflictos de competencias horizontales y verticales.

8. Control de omisiones inconstitucionales.

9. Procesos colectivos.

En estos procesos debe examinarse la legitimación activa, los requisitos de admisibilidad, el procedimiento, la sentencia y recursos. 
Debemos señalar asimismo que, desde una perspectiva metodológica y pedagógi$\mathrm{ca}$, aun cuando es parte del derecho constitucional y no del derecho procesal constitucional, nos parece adecuado integrar a este Syllabus una unidad dedicada al derecho fundamental a la jurisdicción o tutela judicial efectiva y a los elementos y atributos integrantes del debido proceso en el ámbito constitucional, lo que debiera incorporarse entre la primera y la segunda unidad propuesta del Syllabus.

\section{EL DESARROLLO DEL DERECHO PROCESAL CONSTITUCIONAL EN SU ESTUDIO JURÍDICO CIENTÍFICO EN SU ESTUDIO FORMAL ACADÉMICO UNIVERSITARIO Y EN SU DESARROLLO JURÍDICO POSITIVO EN LATINOAMÉRICA}

En el ámbito latinoamericano constitucionalistas y procesalistas se han unido, desde la última década del siglo XX, en los esfuerzos por desarrollar y precisar el derecho procesal constitucional como disciplina jurídica, la que ha ido adquiriendo un desarrollo sostenido en este último decenio.

\subsection{El Instituto Iberoamericano de Derecho Procesal Constitucional}

En 1991 fue creado el Centro Iberoamericano de Derecho Procesal Constitucional, el cual fue reformulado en 2003 como Instituto Iberoamericano de Derecho Procesal Constitucional, 77 junto con la realización del Primer Encuentro Iberoamericano de Derecho Procesal Constitucional conjuntamente con las VII Jornadas A rgentinas de Derecho Procesal Constitucional, en la Pontificia Universidad Católica de Nuestra Señora del Rosario, Rosario, Argentina. Dicho instituto ha impulsado la realización diversos Encuentros Latinoamericanos; a su vez, se han ido creando asociaciones nacionales en Argentina, Chile, Colombia, M éxico y Perú, las cuales organizan periódicamente diversos eventos académicos sobre la materia.

\subsection{La Revista Iberoamericana de Derecho Procesal Constitucional y otras publicaciones dedicadas a la materia en Latinoamérica}

El impulso por el estudio y análisis jurídico científico del derecho procesal constitucional ha encontrado un canal importante en la creación de la Revista Iberoamericana de Derecho Procesal Constitucional con el patrocinio del Instituto Iberoamericano de Derecho Procesal Constitucional y editada por la Editorial Porrúa de M éxico. Asimismo, el Anuario de Derecho Constitucional Latinoamericano ha establecido una sec-

77 Ver Acta Constitutiva del Instituto Iberoamericano de Derecho Procesal Constitucional, en Revista Iberoamericana de Derecho Procesal Constitucional, № 1, enero-junio 2004. Ed. Porrúa, M éxico, pp. 311-312. 
ción de la revista dedicada al derecho procesal constitucional, como asimismo, la Revista Estudios Constitucionales del Centro de Estudios Constitucionales de Chile, tiene declarada como área de desarrollo de contenidos y análisis el derecho procesal constitucional. No puede dejar de mencionarse, en el ámbito Iberoamericano el esfuerzo desarrollado dentro del Centro de Estudios Políticos y Constitucionales de España, dentro del cual bajo la dirección de Francisco Fernández Segado, se publica el Anuario Iberoamericano de Justicia Constitucional.

\subsection{Los Encuentros Iberoamericanos de Derecho Procesal Constitucional}

En el ámbito Iberoamericano, se han desarrollado ya varios Encuentros Iberoamericanos de Derecho Procesal Constitucional, el primero de ellos desarrollado en Rosario, Argentina; el Segundo Encuentro Iberoamericano se desarrolló en San José de Costa Rica, con el Patrocinio de la Corte Suprema, en su Sala Constitucional, en 2004; el Tercer Encuentro Iberoamericano se desarrolló con el patrocinio de la Corte Constitucional de Guatemala, en la ciudad de Antigua, Guatemala, el año 2005; el Cuarto Encuentro Iberoamericano se desarrolló en Santiago organizado por el Centro de Estudios Constitucionales de Chile de la Universidad de Talca y la Facultad de Derecho de la Universidad Diego Portales, con el patrocinio del Tribunal Constitucional, de las A sociaciones Chilenas de Derecho Constitucional y Derecho Procesal Constitucional, del Tribunal Constitucional de Chile y del Senado de la República, en 2006; el Quinto Encuentro Iberoamericano de Derecho Procesal Constitucional se celebró con el patrocinio de la Corte Suprema de Justicia de México en Cancún, M éxico, en 2008.

\subsection{El desarrollo de la enseñanza del derecho procesal constitucional como asignatura en pregrado en las escuelas de derecho en A mérica Latina}

En Argentina, en 1986, Néstor Sagüés inauguró la cátedra de Derecho Procesal Constitucional profundizado en la Universidad Notarial argentina, en la cual se desempeñaba como profesora adjunta M aría M ercedes Sierra Rad. ${ }^{78}$

El derecho procesal constitucional se imparte como asignatura optativa en diversas universidades argentinas, como son la Pontificia Universidad Católica Argentina; Universidad Nacional de Rosario, en el ciclo profesional orientado de la Universidad de Buenos A ires; ${ }^{79}$ en la Facultad de Derecho y Ciencias Sociales de la Universidad de

78 Serra Rad, María Mercedes (1992). Procesos y recursos constitucionales (Buenos Aires, Ed. Depalma). Nota 63, p. 43.

79 SAGUÉs, Néstor Pedro, en respuesta a encuesta en García Belaúnde, Domingo y Espinosa-Saldaña Barrera, Eloy (Coords.) (2006). Encuesta sobre Derecho Procesal Constitucional (México, D.F. Ed. Porrúa, e Instituto Mexicano de Derecho Procesal Constitucional), p. 28. 
Córdoba desde el año 2000, como asignatura obligatoria, ${ }^{80}$ como asimismo, en las Universidades de Mar del Plata y Tucumán. ${ }^{81}$

En Bolivia, dos universidades en Santa Cruz la han incorporado como cursos de pregrado, la Universidad Privada de Santa Cruz (UPSA), la imparte desde el año 2001 en octavo semestre de la carrera de Derecho y la Universidad Técnica Privada de Santa Cruz (UTEPSA ), desde 2003 la ha incorporado al plan de estudios de la carrera de derecho. ${ }^{82}$

En Brasil se enseña en el plan de estudios de la carrera de derecho de la Universidad Federal de Ceará, en la Facultad de Derecho de la Universidad de Recife (Pernambuco), aún cuando la mayoría de las Universidades lo desarrollan como justicia constitucional o jurisdicción constitucional.

En Chile, a nivel de pregrado se ha desarrollado en cursos electivos en la Facultad de Derecho de la Universidad de Talca (1998-2002) y en la Universidad Central de Chile en cursos desarrollados por los profesores Francisco Zúñiga y Perramont.

En Colombia, el curso de derecho procesal constitucional se incluye en la Universidad de la Sabana y como módulo de especialidad en derecho constitucional en la Universidad Autónoma de Bucaramanga.

En Costa Rica, integra el plan de estudios de Bachiller en Derecho de la Escuela Libre de Derecho, como de la carrera de derecho de la Universidad Autónoma de Centroamérica, en el sexto cuatrimestre.

En Guatemala, se imparte en décimo semestre en la Facultad de Ciencias Jurídicas y Sociales de la Universidad M esoamericana como Derecho procesal constitucional y administrativo.

En El Salvador, se desarrolla en las Universidades de El Salvador, la Universidad Capitán General Gerardo Barrios y en la Universidad Centroamericana José Simeón Cañas, en las respectivas carreras de derecho.

En México, en las Universidades Nacional Autónoma de México desde 2008, en la Universidad Autónoma de Baja California en las facultades de derecho de Tijuana y M exicali, conforme a su plan de estudios de 1999; en la Universidad Autónoma Benito Juárez de Oaxaca, desde 2008; en la Universidad Autónoma de Chiapas, en la

80 Ferrer Mac-Gregor, Eduardo (2008). Derecho Procesal Constitucional (Madrid, Ed. Marcial Pons), nota 47, p. 34.

81 Gozaínı, Osvaldo, en respuesta a encuesta, en García Belaúnde, Domingo y Espinosa-Saldaña Barrera, Eloy (Coords.) (2006). Encuesta sobre Derecho Procesal Constitucional México, D.F. Ed. Porrúa, e Instituto Mexicano de Derecho Procesal Constitucional), p. 27.

82 Asbún, Jorge en respuesta a encuesta en García Belaúnde, Domingo y Espinosa-Saldaña Barrera, Eloy (Coords.) Encuesta sobre Derecho Procesal Constitucional, Ed. Porrúa e Instituto M exicano de Derecho Procesal Constitucional, México, 2006, p. 29. 
Universidad de Colima, en la Universidad de Guadalajara, en la Universidad Autónoma de Nueva de León; en la Universidad Autónoma de Tlaxcala, Universidad Autónoma de Sinaloa, Universidad autónoma de Yucatán, Universidad Panamericana, Universidad Iberoamericana, Universidad A náhuac, Universidad La Salle, Universidad M odelo, Universidad Americana de A capulco, entre otras. ${ }^{83}$

En Panamá, se imparte como curso en el noveno cuatrimestre en la Universidad Cristiana de Panamá.

En Perú, el derecho procesal constitucional se imparte en la Universidad Nacional Mayor de San Marcos desde 1992 con carácter obligatorio, en el sexto año;84 lo mismo ocurre desde 1996 en la Universidad Nacional de Trujillo y en la Universidad Privada Antenor Orrego de Trujillo, posteriormente se desarrolló el curso en la Universidad César Vallejo y en la Universidad Privada del Norte, ${ }^{85}$ en la Universidad de Lima y en la Universidad San M artín de Porres; ${ }^{86}$ como desde 2003 y con el mismo carácter obligatorio en la Pontificia Universidad Católica del Perú. En la actualidad se estudia en muchas universidades como disciplina autónoma, luego de la dictación del Código Procesal Constitucional que entró en vigencia en diciembre de 2004.

\subsection{La enseñanza del derecho procesal constitucional en postgrado en América Latina}

En A rgentina, el primer curso de postgrado de Derecho Procesal Constitucional fue impartido por Néstor Pedro Sagüés en la Universidad de Belgrano, en 1982. El Derecho Procesal Constitucional fue incorporado como curso de doctorado en la Universidad del Rosario, en la Facultad de Derecho y Ciencias Sociales, desde 1988.

En Bolivia, a nivel postgrado el Derecho Procesal Constitucional se imparte en la Maestría de Derecho Constitucional y Derecho Procesal Constitucional en la Universidad Andina Simón Bolívar, en la ciudad de Sucre, como en su subsidiaria de la Ciudad de La Paz, en la Universidad San Simón de Cochabamba, en la Universidad mayor Gabriel René Moreno de Santa Cruz de la Sierra. ${ }^{87}$

83 FerRer MAC-Gregor, Eduardo (2008). Derecho procesal constitucional (Madrid, Ed. Marcial Pons), pp. 36-37.

84 Rodriguez Domínguez, Elvito (2006). Manual de Derecho Procesal Constitucional (Lima, Ed. Grijley), p. 121.

85 Eто CRUZ, Gerardo. En respuesta a cuestionario en García Belaúnde, Domingo y Espinosa-Saldaña Barrera, Eloy (Coords.) (2006). Encuesta sobre Derecho Procesal Constitucional (M éxico D.F. Ed. Porrúa e Instituto Mexicano de Derecho Procesal Constitucional), p. 99.

86 Quiroga León, Aníbal. En respuesta a cuestionario en García Belaúnde, Domingo y Espinosa-Saldaña Barrera, Eloy (Coords.) (2006). Encuesta sobre Derecho Procesal Constitucional (M éxico D.F. Ed. Porrúa e Instituto M exicano de Derecho Procesal Constitucional), p. 104, nota 7.

87 Rivera SAntibáñez, José Antonio en respuesta a encuesta en García Belaúnde, Domingo y EspinosaSaldaña Barrera, Eloy (Coords.) (2006). Encuesta sobre Derecho Procesal Constitucional (M éxico D.F. Ed. Porrúa e Instituto Mexicano de Derecho Procesal Constitucional), p. 34. 
En Chile, la enseñanza de postgrado se encuentra concentrada en el Magíster en Derecho Constitucional con mención en Derecho Procesal Constitucional del Centro de Estudios Constitucionales de Chile, Campus Santiago de la Universidad de Talca.

En Costa Rica, según precisa el profesor Rubén Hernández Valle, en la actualidad, "se imparte prácticamente en todas las Facultades de Derecho del país, tanto públicas como privadas". ${ }^{88}$

En Colombia, en la Maestría en Derecho Procesal de la Universidad de Medellín.

En México, en la Universidad Panamericana en la maestría en Derecho Procesal Constitucional con duración de dos años, desde 2002; en la maestría de Derecho Constitucional de la Universidad Nacional Autónoma de M éxico, desde 2003; a partir de 2003 se realizan con regularidad diplomados de Derecho Procesal Constitucional en las cuatro decenas de Casas de la Cultura de la Suprema Corte de Justicia de la Nación. ${ }^{89}$

\subsection{El desarrollo de la legislación procesal constitucional en forma sistemática y el desarrollo de los códigos de derecho procesal constitucional}

Estos esfuerzos han comenzado a tener frutos en el ámbito del derecho positivo, con la aprobación de códigos de derecho procesal constitucional como son la ley 7.135 de Jurisdicción constitucional de Costa Rica; la ley $N^{\circ} 7.135$ de jurisdicción constitucional de 1989; la ley de amparo, exhibición personal y constitucionalidad de Guatemala de 14 de enero de 1986 (Decreto $N^{\circ} 1-86$ de la Asamblea Constituyente); la ley $N^{\circ} 8.369$ de Procedimientos Constitucionales de la Provincia de Entre Ríos y el Código Procesal Constitucional de la Provincia de Tucumán (Ley 6944 de 1995 y que se encuentra vigente desde el 7 de mayo de 1999, en Argentina; ${ }^{90}$ el Código de Derecho Procesal Constitucional del Perú (ley N² 28.237 de 2004), ${ }^{91}$ para señalar algunas normativas sistemáticas sobre la materia.

88 Hernández Valle, Rubén. En respuesta a encuesta en García Belaúnde, Domingo y Espinosa-Saldaña Barrera, Eloy (Coords.) (2006). Encuesta sobre Derecho Procesal Constitucional (M éxico D.F. Ed. Porrúa e Instituto Mexicano de Derecho Procesal Constitucional), p. 52.

89 Ferrer M AC-Gregor, Eduardo (2008). Derecho procesal constitucional (Madrid, Ed. Marcial Pons), pp. 36-37.

90 Sobre dicho código puede verse, SAGÜÉs, Néstor Pedro (2000). “El Código Procesal Constitucional de la Provincia de Tucumán", en Bidart Campos, Germán (Coord.). El derecho constitucional del siglo XXI. Diagnóstico y perspectivas. Ed. Ediar, Buenos Aires, pp. 461 y ss. Reeditado en SAgüÉs, Nestor Pedro (2006). Derecho procesal constitucional. Logros y obstáculos (Buenos Aires, Ed. Ad-Hoc y Konrad Adenauer Stifftung), pp. 53-72.

91 Sobre dicho Código ver: Espinosa-Saldaña Barrera, Eloy (2004). Código Procesal Constitucional. Serie Derechos y Garantías (Lima, Ed. Palestra). Obra colectiva A bad Yupanqui, Samuel y otros (2003). Código Procesal Constitucional. Anteproyecto y Legislación vigente (Lima, Palestra Editores). QuIROGA LEÓn, A níbal (2005). Derecho Procesal Constitucional y el Código Procesal Constitucional (Lima, ARA Editores). 


\subsection{El desarrollo del derecho procesal constitucional en la doctrina jurídica latinoamericana}

En M éxico, además de Héctor Fix Zamudio, padre y creador de la disciplina jurídica del derecho procesal constitucional, en las generaciones más jóvenes de juristas mexicanos que han continuado el desarrollo de la disciplina pueden destacarse a José Ovalle Favela, en su obra Teoría General del Proceso, Oxford, M éxico, 2003, que trata específicamente del derecho procesal constitucional como rama del derecho procesal. El impulsor más dinámico del desarrollo de la disciplina del derecho procesal constitucional en México hoy es el joven académico y procesalista Eduardo Ferrer Mac-Gregor, cuyos trabajos han sido recopilados en el libro Estudios sobre Derecho Procesal Constitucional (Ed. Porrúa, México, 2006). Siendo, asimismo el coordinador del mayor esfuerzo de compilación de trabajos sobre la materia desarrollada hasta el presente en latinoamérica, en el colectivo que fue publicado por primera vez en 2001 , y que hoy ya tiene, luego de diversas ediciones, cuatro tomos, denominado Derecho Procesal Constitucional (cuarta edición 2003, reimpreso en 2006). Dicho académico ha sido también el fundador de la colección de Editoral Porrúa, dedicada al derecho procesal constitucional, que ha reunido un importante número de publicaciones de autores dedicados a la disciplina de toda A mérica Latina, acercándose ya a una treintena de libros sobre la materia. A su vez, Eduardo Ferrer Mac-Gregor dirige con acierto la Revista Iberoamericana de Derecho Procesal Constitucional desde su fundación y cuyo primer número apareció en 2004, teniendo desde ese primer semestre de ese año un desarrollo ininterrumpido de números correspondientes al primer y segundo semestre de cada año.

En Perú, el vocablo derecho procesal constitucional fue introducido por el destacado constitucionalista Domingo García Belaúnde, en su texto El Habeas Corpus interpretado (Instituto de Investigaciones Jurídicas, Universidad Católica, Lima, 1971). El autor desarrollará luego diversas obras que reflexionarán y profundizarán sobre el tema en análisis, entre ellas, Derecho Procesal Constitucional (Universidad César Vallejo, Trujillo, 1998), la cual tiene una edición colombiana de Editorial Temis, Bogotá, 2001; De la jurisdicción constitucional al derecho procesal constitucional (Ed. Grijley, Lima, cuya cuarta edición peruana es de 2002, la cual cuenta también con edición mexicana). El análisis de la materia culmina con una recopilación de artículos y monografías publicadas como libro El desarrollo procesal constitucional en perspectiva (Ed. Porrúa, M éxico, 2008).

El primer libro que lleva en Perú un título directo sobre derecho procesal constitucional es Introducción al Derecho Procesal Constitucional, del constitucionalista Gerardo Eto Cruz, siendo publicado en Trujillo en 1990 y 1992. Otra obra de calidad se debe al procesalista y profesor de la Universidad de San Marcos, Elvito Rodríguez Domínguez en su libro Derecho Procesal Constitucional (Ed. Grijley, Lima, 1997), la que ya lleva una tercera edición en 2006, con prólogo de Héctor Fix Zamudio, con el título Manual de Derecho Procesal Constitucional. Ed. Grijley, Lima, 2006.

A su vez César Landa, distinguido constitucionalista y magistrado del Tribunal Constitucional del Perú, del cual fue Presidente, desarrolla dos obras que merecen ser des- 
tacadas, su Teoría del derecho procesal constitucional (Editorial Palestra, Lima, 2004); y sus Estudios sobre Derecho Procesal Constitucional (Ed. Porrúa, México, 2006), el cual se sitúa en la doctrina peruana en la tesis del distinguido constitucionalista alemán Peter Häberle que considera al derecho procesal constitucional como parte del derecho constitucional, como un derecho constitucional concretizado.

Un constitucionalista peruano, de una generación más joven, Samuel A bad Yupanqui, publica una obra sistemática de gran calidad con el título de Derecho Procesal Constitucional (Ed. Gaceta Jurídica, Lima, 2004).

Desde la perspectiva procesal, el académico de la Pontificia Universidad Católica del Perú, A níbal Quiroga León, recopila diversos trabajos en el texto “Derecho Procesal Constitucional y el Código Procesal Constitucional" (A ra Ediciones, Lima, 2005).

En los trabajos colectivos sobre la materia concretados en Perú, cabe destacar el desarrollado bajo la coordinación de Susana Castañeda Otsu, Derecho Procesal Constitucional (Jurista Editores, dos volúmenes, Lima, 2004); como asimismo la obra en dos tomos, El derecho procesal constitucional peruano, en homenaje a Domingo García Belaunde (Editorial Grijley, Lima, 2005); puede señalarse también el texto coordinado por José Palomino M anchego y Gerardo Eto Cruz, El pensamiento vivo de Héctor Fix Zamudio (con especial referencia al Derecho Procesal Constitucional), Cuadernos del Rectorado $N^{\circ} 11$, Universidad Inca Garcilaso de la Vega, Lima, primera edición 2005, tercera edición, agosto de 2008); y la obra colectiva coordinada por Walter Carnota y Patricio M araniello Derechos Fundamentales, Derecho Constitucional y Procesal Constitucional (Ed. San Marcos, Lima, 2008).

En Argentina, el derecho procesal constitucional se desarrolla de la mano de la obra del constitucionalista Néstor Pedro Sagüés, quien publica el libro Ley de A mparo por Editorial Astrea, Buenos Aires, en 1979, en el cual hace referencia al amparo como institución de derecho procesal constitucional, desarrollando su concepción madura sobre la materia en su artículo "Derecho Procesal Constitucional y jurisdicción constitucional" (La Ley, 1981, C, pp. 865-871).

Néstor Pedro Sagüés considera en su obra Recurso Extraordinario (1984), que es poco adecuado atribuirle a Kelsen la paternidad histórica del derecho procesal constitucional, en la medida que los procesos constitucionales de habeas corpus y amparo, como el principio de supremacía constitucional son anteriores, ${ }^{92}$ siendo su obra culmine en esta materia su Derecho Procesal Constitucional en cuatro tomos, editado a partir de la década de los años ochenta del siglo pasado, con varias ediciones y actualizaciones, cuyos dos primeros volúmenes se dedican al recurso extraordinario, el tercero al amparo y el cuarto, al Habeas Corpus. En el primer tomo, Sagüés desarrolla su análisis sobre el derecho procesal constitucional retomando sustantivamente su

92 SAGüÉs, Néstor Pedro (1984). Recurso Extraordinario. Tomo I (Buenos Aires, Ed. Depalma), pp. 11 y sS. 
ensayo de 1981, dando un enfoque unitario a los cuatro tomos como instituciones del derecho procesal constitucional argentino.

El profesor Sagüés es asimismo el impulsor de la creación del Centro Iberoamericano de Derecho Procesal Constitucional teniendo como apoyo la Universidad Católica de Rosario, de 1992, que luego dará paso al Instituto iberoamericano de Derecho procesal constitucional en 2003, con ocasión del Primer Encuentro Iberoamericano de Derecho Procesal Constitucional del 21 al 12 de agosto de 2003 en Rosario, Argentina.

Sus más recientes obras sobre la materia han sido El sistema de derechos, magistratura y procesos constitucionales en América Latina (Ed. Porrúa, M éxico, 2004) y Derecho procesal constitucional. Logros y obstáculos(Ed. Ad-Hoc, Buenos Aires, 2006).

La profesora María Mercedes Serra, en su obra Procesos y recursos constitucionales (Ediciones Depalma, Buenos Aires, 1992) desarrolla también algunos aspectos del derecho procesal constitucional.

En el ámbito del constitucionalismo argentino, en derecho procesal constitucional ha tenido un amplio desarrollo en la Universidad Nacional de Córdoba, donde el académico Alfredo M oney desarrolla su Derecho Procesal Constitucional (Ed. de la Docta, Córdoba, 2002) y dos años más tarde, sus Elementos de Derecho Procesal Constitucional (Ed. Advocatus, Córdoba, tomo I (2004) y tomo II (2005).

En Argentina también han asumido el derecho procesal constitucional algunos procesalistas. sin mayores consideraciones dogmáticas específicas, dentro de los cuales puede contarse a A ugusto M orello, en su obra Constitución y Proceso (Librería Editora Platense, Buenos Aires - La Plata, 1998).

Dentro del procesalismo argentino, será Juan Carlos Hitters, distinguido procesalista y magistrado de la Corte Suprema de La Plata, el que dedique un análisis pertinente y específico al derecho procesal constitucional, en un ensayo titulado "El derecho procesal constitucional", publicado en El Derecho, tomo 121, 1987; las obras posteriores de Hitters se han dedicado a temas de derecho procesal y derecho internacional de los derechos humanos. También desde la perspectiva del derecho procesal, Osvaldo Gozaíni, profesor de la Universidad de Buenos Aires, desarrolla su perspectiva del derecho procesal constitucional principalmente en sus obras La Justicia Constitucional (Ed. Depalma, Buenos Aires, 1994), y su libro publicado en México, El derecho procesal constitucional y los derechos humanos ( Ed. UNAM, México, 1995). El autor desarrollará asimismo su Derecho Procesal Constitucional, en cinco tomos, siguiendo la huella de Sagüés. Su obra más reciente sobre la materia en Argentina es su libro Introducción al derecho procesal constitucional (Rubinzal Culzoni Editores, Buenos Aires, 2006).

Dentro de la generación más joven de constitucionalistas preocupados por el tema, puede mencionarse a Pablo Luis Manili, quien ha coordinado la obra colectiva Derecho Procesal Constitucional (Editorial Universidad, Buenos Aires, 2005). 
También dentro de las obras recientes cabe consignar la de Mario Masciotra y Enrique Carrelli quien dirige y coordina Derecho Procesal Constitucional ( Ed. Ad-Hoc, Buenos Aires, 2006).

En Brasil, consideramos que José Frederico Márquez, en su obra Instituicoes de Direito Processual Civil (Editora Forense, Río de Janeiro, 1958), precisa que el control jurisdiccional de constitucionalidad genera un proceso constitucional, lo que legitima referirse a un derecho procesal constitucional. El autor considera que, en el derecho brasileño, es objeto de un proceso constitucional toda pretensión que descansa en una regla emanada de la Constitución.

El primer libro que se refiere en forma más científica al derecho procesal constitucional, es el del constitucionalista Alfredo de Oliveira Baracho, denominado Processo Constitucional (Editorial Forense, Río de Janeiro, 1984, en la cual asume la tesis del profesor Héctor Fix Zamudio de la diferenciación entre derecho procesal constitucional y derecho constitucional procesal, con un adecuado análisis de doctrina comparada, lo cual es reiterado en su compilación de ensayos, en el libro Direito Processual Constitucional (Ed. Fórum, Belo Horizonte, 2006), cuyas primeras 80 páginas las dedica a la teoría general del proceso constitucional.

En una línea similar, se encuentra la obra de Andres Ramos Tavarés, Tribunal e jurisdicao constitucional (Celso Bastos Editor, Sao Paulo, 1998), el cual considera el derecho procesal constitucional y el derecho constitucional procesal como parte de la jurisdicción constitucional, lo que desarrolla en forma más sistemática en su libro Teoria da Justica Constitucional (Edit. Saraiva, Sao Paulo, 2005). A su vez, Andrés Ramos Tavarés, en su libro Curso de Direito Constitucional precisará que "El derecho procesal constitucional es el conjunto de reglas procedimentales fundamentadoras de la práctica del control jurisdiccional, autónomo o no, de la constitucionalidad del comportamiento estatal", ${ }^{93}$ así señala el autor considerado, el derecho procesal constitucional debe servir a la actuación del Texto Constitucional, solucionando los problemas de naturaleza constitucional" ${ }^{94}$ En una perspectiva similar, se encuentra la obra postrera del destacado constitucionalista brasilero José Alfredo de Oliveira Baracho, Direito Processual Constitucional. Aspectos contemporáneos (Ed. Fórum, Belo Horizonte, 2006), donde el autor en la parte introductoria del texto, dedicada a la teoría del proceso constitucional se refiere a un tratamiento de los contenidos con proceso constitucional o derecho procesal constitucional, los cuales pasan a estar impregnados de los institutos procesales, siguiendo las categorías o bases del proceso constitucional. ${ }^{95}$

93 Ramos Tavarés, André (2006). Curso de Direito Constitucional, Cuarta edición (São Paulo, Editora Saraiva), p. 230.

94 Ramos TAVARÉs, André (2006). Curso de Direito Constitucional, Cuarta edición (São Paulo, Editora Saraiva), p. 231.

95 Oliveira Baracho, José Alfredo de (2006). Direito Processual Constitucional (Belo Horizonte, Ed. Fórum), p. 28. 
Marcelo Cattoni de Oliveira, publica su Direito processual constitucional (Ed. M andamentos, Belo Horizonte, 2001), luego de una primera parte, dedicada a la interpretación jurídica, algunos temas de teoría de la argumentación, de derechos fundamentales y de tutela jurisdiccional y Estado democrático de derecho, en una segunda parte, aborda el una segunda parte, el derecho procesal constitucional, previo análisis de la teoría discursiva de la Constitución y algunas consideraciones críticas sobre las normas constitucionales programáticas, considerando el proceso constitucional como instrumento de la jurisdicción constitucional, para Cattoni, la jurisdicción constitucional significa el ejercicio del poder jurisdiccional en materia constitucional, sea en sede difusa o concentrada, de alegaciones que se fundan en razones de constitucionalidad o inconstitucionalidad, en un contexto lógico-argumentativo de aplicación reconstructiva del Derecho Constitucional, ${ }^{96}$ aun cuando señala que la diferenciación entre derecho procesal constitucional y derecho constitucional es superflua y no tiene sentido, ya que todo proceso debe ser constitucional por su adecuación a la Constitución, el autor señala que "así, cae por tierra, en Brasil, una teoría constitucional o procesal que pretenda absolutizar la distinción entre derecho constitucional procesal y derecho procesal constitucional. Todo proceso, y no solamente los que estructuran las llamadas garantías constitucionales-procesales, al crear las condiciones institucionales de un discurso lógico-argumentativo de aplicación reconstructiva del derecho constitucional, el proceso que instrumentaliza el ejercicio de la jurisdicción en materia constitucional, o sea, el proceso constitucional". ${ }^{97}$ Para Cattoni, el derecho procesal constitucional formado a partir de las normas procesales de la organización de la justicia constitucional y de los instrumentos procesales previstos en las constituciones a efectos de "garantizar la Constitución" y la "garantía de los derechos fundamentales", control de constitucionalidad, solución de conflictos entre los órganos de cúpula del Estado, resolución de conflictos federativos o regionales, el juzgamiento de agentes políticos, recurso constitucional, Habeas Corpus, Amparo, Mandamiento de seguridad (mandado de Seguranza), Habeas Data, etc.. ${ }^{98}$ esta perspectiva para el autor analizado "[... ] es una distinción problemática a la luz de una teoría constitucional constitucionalmente adecuada del derecho brasilero", en la medida que el derecho constitucional es el fundamento de validez de todo el ordenamiento jurídico, ya que establece el procedimiento a través del cual todas las demás normas son producidas, no habiendo derecho procesal que no deba ser, en este sentido constitucional, asimismo, en Brasil el control de constitucionalidad puede darse como preliminar de mérito de cualquier proceso, pudiendo todo ciudadano argumentar una inconstitucionalidad a cualquier juez de primera a última instancia, el cual debe apreciar la constitucionalidad de la ley o de cualquier acto normativo, pudiendo determinar su inconstitucionalidad, por lo que toda jurisdicción es jurisdicción constitucional. ${ }^{99}$

\footnotetext{
96 Cattoni, Marcelo (2001). Direito Processual Constitucional (Belo Horizonte, Ed. Mandamentos), p. 206.

97 Cattoni, Marcelo (2001), p. 207.

98 Cattoni, Marcelo (2001), pp. 211-212.

99 CAttoni, Marcelo (2001), pp. 212-214.
} 
A su vez, Paulo Bonavides, constitucionalista de sólida trayectoria en Brasil, en su Curso de Direito Constitucional (M alheiro editores, Sao Paulo, 2003), se refiere a los vínculos estrechos entre el derecho constitucional y el derecho procesal, del cual nace una nueva disciplina en desarrollo que es el derecho procesal constitucional.

El constitucionalista Ivo Dantas, en su libro Constituicao y processo. Tomo I: Introducao ao Direito Processual Constitucional (Jurua Editora, Curitiva, 2003), analiza, fundamenta y asume la existencia de un derecho procesal constitucional que analiza la jurisdicción constitucional y la jurisdicción protectora de los derechos fundamentales y un derecho constitucional procesal, que además de señalar la existencia de un derecho constitucional judicial, que tiene por objeto el estudio del Poder Judicial, el M inisterio Público y la abogacía. Por último, cabe mencionar la obra de Paulo Hamilton Siqueira Jr., Direito Processual Constitucional (Editora Saraiva, Sao Paulo, 2006).

Desde la perspectiva del derecho procesal, cabe destacar la obra colectiva de Antonio Carlos de Araujo Cintra, Ada Pellegrini Grinover y Candido Rangel Dinamarco, Teoria Geral do Processo (M alheiros editores, Sao Paulo, 2006); en cuyo capítulo V al derecho procesal constitucional.

En Colombia, es Ernesto Rey Cantor, ex magistrado, profesor de derecho constitucional, entre otras universidades y escuelas de derecho, en la Universidad libre de Santa $\mathrm{Fe}$, en la Universidad Javeriana, en la Universidad Externado y en la Universidad Católica, además de juez ad hoc de la Corte Interamericana de Derechos Humanos, es quien ha socializado e impulsado el estudio del derecho procesal constitucional en Colombia, el cual define el derecho procesal constitucional, como "el conjunto de principios y normas jurídicas contenidas en la Constitución y la ley, que regulan los procesos constitucionales y los procedimientos constitucionales, cualquiera que sean los órganos encargados de preservar con justicia la supremacía de la Constitución y la protección de los derechos fundamentales", 100 ampliando la conceptualización anteriormente formulada en su libro Introducción al derecho procesal constitucional (Controles de Constitucionalidad y legalidad), donde había sostenido que el derecho procesal constitucional podía definirse como "un conjunto de normas jurídicas en la Constitución y la ley, que regulan las actuaciones y procesos constitucionales, cualquiera que sean los órganos encargados de preservar la supremacía de la Constitución" ${ }^{101} \mathrm{El}$ autor ha sido un socializador en Colombia de las tesis de Fix Zamudio.

En la misma perspectiva, pero con menor protagonismo, encontramos al profesor de derecho constitucional Hernán A lejandro Olano, el cual se refiere brevemente a la

100 Rey Cantor, Ernesto. “Derecho Procesal Constitucional en Colombia”, en Ferrer Mac-Gregor, Eduardo. (Coordinador) (2002). Derecho Procesal Constitucional. Tomo III, Tercera edición (México D.F. Ed. Porrúa), p. 2363.

101 ReY CANTOR, Ernesto (1994). Introducción al derecho procesal constitucional (Controles de Constitucionalidad y legalidad). (Cali, Ed. Universidad Libre), p. 29. 
materia en su libro Derecho Constitucional O rgánico, ${ }^{102}$ donde realizando algunas consideraciones de autores en la materia como Fix Zamudio, García Belaúnde, Bidart Campos y Gozaíni, considera que la disciplina tiene como componentes el estudio de la jurisdicción, las garantías constitucionales, los procesos y los órganos de jurisdicción constitucional. ${ }^{103}$ En Colombia, existe un incipiente desarrollo de la disciplina, donde se han realizado algunos seminarios sobre la materia en las Escuelas de Derecho de la Universidad del Rosario y la Universidad de Los Andes, en los últimos años, aun cuando la disciplina no se encuentra en los pre o postgrados de ninguna de las Universidades colombianas.

En Chile, el vocablo ha sido socializado por Humberto Nogueira Alcalá, ${ }^{104}$ quien toma la iniciativa del desarrollo de un Primer Seminario Latinoamericano en la Facultad de Derecho de la Universidad Central en Santiago, en octubre de 1987, al que fueron invitados distinguidos constitucionalistas de América Latina y Europa, el que fue publicado en La Revista de Derecho de esa Facultad, número 1 de enero-junio de 1988 y número 1 de enero-junio de 1989. Al que le sigue un segundo seminario internacional denominadas "Segundas Jornadas de Derecho Procesal Constitucional" que se llevaron a cabo en la Universidad Central, en abril de 1991, dentro de cuyos invitados contamos con Héctor Fix Zamudio, publicándose las ponencias en La Revista de Derecho de la Facultad de Derecho de la Universidad Central en su $N^{\circ} 2$ de juliodiciembre de 1990 y N$^{\circ} 1$ de enero-junio de 1991.

A su vez, bajo el decanato de Humberto Nogueira en la Facultad de Ciencias Jurídicas de la Universidad de Talca, se integró al plan de estudios de la Carrera de Derecho como curso electivo el derecho procesal constitucional, el cual luego fue eliminado del plan de estudios en la perspectiva de su incorporación al Magíster en Derecho Constitucional que se desarrollaría, una vez creado el Centro de Estudios Constitucionales de Chile, en el Campus Santiago de la Universidad de Talca, cuya dirección fue encomendada por la rectoría al profesor y ex Decano Humberto Nogueira, donde efectivamente se prepara y aprueba por las instancias académicas de la Universidad, el desarrollo de un Magíster en Derecho Constitucional con mención en Derecho Procesal Constitucional, el cual comienza en 2005, y en el segundo semestre de 2008 comenzó su tercera versión.

Asimismo, tuvimos el honor de organizar con el respaldo del Instituto Iberoamericano de Derecho Procesal Constitucional y los patrocinios y apoyos del Centro de Estudios Constitucionales de Chile de la Universidad de Talca y de la Facultad de Dere-

102 OLANO GARCÍA, Hernán Alejandro (2004). Derecho Constitucional Orgánico. Estructura y Funciones del Estado (Bogotá, Ed. Doctrina y Ley Ltda.).

103 Olano García, Hernán Alejandro (2004). Derecho Constitucional Orgánico. Estructura y Funciones del Estado (Bogotá, Ed. Doctrina y Ley Ltda), pp. 278-279.

104 Ver, GozAinı, Osvaldo Alfredo (2006). Introducción al derecho procesal constitucional (Buenos Aires, Rubinzal-Culzoni Editores), p. 54. García BelaúndE, Domingo (2008). El derecho procesal constitucional en perspectiva (M éxico D.F. Ed. Porrúa), pp. 23-25. 
cho de la Universidad Diego Portales, del Tribunal Constitucional chileno, de la A sociación Chilena de Derecho Constitucional y de la A sociación de Derecho Procesal Constitucional, el "IV Encuentro Iberoamericano de Derecho Procesal Constitucional" que tuvo como tema central Los desafíos del derecho procesal constitucional a inicios del siglo XXI, el cual se realiza en el auditorio de la Facultad de Derecho de la Universidad Diego Portales, en noviembre de 2006. Los trabajos de tres días intensos de reflexión con la participación de académicos y magistrados de los diversos países de latinoamérica se publicaron en la Revista Estudios Constitucionales, año 4 N $^{\circ} 2$, de 2006, en un extenso volumen de 802 páginas.

Finalmente, en 2008, hemos coordinado la edición de los trabajos de distinguidos constitucionalistas, procesalistas y magistrados del Tribunal Constitucional chileno, con la denominación de La ciencia del derecho procesal constitucional, ${ }^{105}$ el cual editado por Librotecnia, Santiago, enero de 2009, constituyen parte del merecido homenaje a Héctor Fix Zamudio, que en su obra completa ha sido editada en M éxico en 2008.

En materia de derecho procesal constitucional se distinguen artículos y monografías desarrollados por el distinguido procesalista y Presidente del Tribunal Constitucional de Chile, Juan Colombo Campbell, como asimismo por Andrés Bordalí de la Universidad Austral de Chile, y por constitucionalistas como Lautaro Ríos Álvarez, Luz Bulnes A Idunate, Eduardo A Idunate L., Emilio Pffefer Urquiaga, Francisco Zúñiga Urbina y Humberto Nogueira Alcalá, entre otros.

Dentro de las obras dedicadas a la materia procesal constitucional cabe mencionar el libro de Bordalí, Temas de Derecho Procesal Constitucional (Ed. Fallos del Mes, Santiago, 2003), en cuyo preámbulo explicita que el derecho procesal constitucional chileno estaría compuesto, además de las competencias del Tribunal Constitucional, por "aquellos procedimientos especiales instituidos para una tutela directa y urgente de los derechos fundamentales, esto es, el proceso de protección, habeas corpus y amparo económico"; ${ }^{106}$ a su vez, el académico y Presidente del Tribunal Constitucional de Chile, Juan Colombo Campbell, aborda el tema desde una perspectiva netamente procesal en diferentes trabajos, respecto de los cuales cabe mencionar Las funciones del derecho procesal constitucional, 2002, ${ }^{107}$ Enfoques conceptuales y caracterización del derecho procesal a principios del siglo XXI (2004) y "El Debido Proceso Constitucional" (Cuadernos del Tribunal Constitucional, $N^{\circ} 32$, año 2006), el cual luego fue publicado en México, por Porrúa. ${ }^{108}$

105 Nogueira AlcalÁ, Humberto (Coord.) (2009). La Ciencia del Derecho Procesal Constitucional. Estudios en homenaje a Héctor Fix-Zamudio, en sus 50 años como investigador del Derecho. Homenaje chileno. (Santiago, Ed. Librotecnia).

106 Bordalí Salamanca, Andrés (2002). Temas de Derecho Procesal Constitucional (Santiago, Editorial Fallos del Mes-Universidad Austral de Chile).

107 Colombo Cam pbelL, Juan (2002). "Funciones del Derecho Procesal Constitucional". Revista lus et Praxis, Vol. $8 \mathrm{~N}^{\circ} 2$ (Talca, Facultad de Ciencias Jurídicas y Sociales), pp. 11-69. Luego, publicado en A nuario de Derecho Constitucional Latinoamericano, Ed. Fundación Konrad Adenauer, 2002.

${ }^{108}$ Colombo Cam pbell, Juan (2007). El debido proceso constitucional. Ed. Porrúa, México, 139 pp. 
A su vez, el profesor de la Universidad Católica de Valparaíso, Eduardo Aldunate, ha escrito un interesante trabajo denominado "El derecho procesal constitucional desde la perspectiva de la Teoría Constitucional", publicado en la Revista de Derecho de la Universidad Católica de Valparaíso NXVIII, 1997.

El tema también ha sido tratado también por el profesor Francisco Zúñiga Urbina en sus Elementos de Jurisdicción Constitucional, dos tomos, Ed. Universidad Central de Chile, Santiago, 2002, tratando la materia en su primer volumen. A su vez, Francisco Zúñiga Urbina, publica "Derecho Procesal Constitucional. El aporte de Domingo García Belaunde a una nueva disciplina" en Palomino Manchego, José (Coord.) El Derecho Procesal Constitucional peruano. Estudios en Homenaje a Domingo García Belaunde. Tomo II. Ed. Jurídica Grijley, Lima, 2005, pp. 1421-1428, en este artículo Zúñiga precisa que "El derecho procesal constitucional surge como una disciplina científica nueva, confluencia de la dogmática procesal y constitucional, que adquiere paulatinamente autonomía científica y disciplinaria", 109 agregando que "El Derecho Procesal Constitucional tiene por objeto la jurisdicción constitucional o en términos sintéticos la judicatura constitucional, las acciones constitucionales y los procesos constitucionales", ${ }^{110}$ concluyendo el artículo el autor señala que "El Derecho Procesal Constitucional es una disciplina novel, pero crecientemente autónoma y con estatus en nuestras universidades, y que constituye un fértil campo de colaboración disciplinaria entre procesalistas y constitucionalistas, que nos permite asumir una tarea desde la Ciencia del Derecho a favor del Estado democrático y del Estado de derecho". ${ }^{111}$

Humberto Nogueira A lcalá ha desarrollado un análisis completo sobre la jurisdicción constitucional y los tribunales constitucionales de A mérica del Sur, cuya primera aproximación fue publicada por la Editorial Porrúa de México con el nombre de "La jurisdicción constitucional y los tribunales constitucionales en Sudamérica en la alborada del siglo XXI", de 2004; el año siguiente el texto en una versión aumentada fue publicada en Santiago de Chile, por la Editorial Jurídica LexisNexis, con el prólogo de Néstor Pedro Sagués, con el título de "La Justicia y los tribunales constitucionales de indoiberoamérica del sur". El mismo texto con adecuaciones debido a la salida de la ley que regula la Sala Constitucional del Tribunal Supremo de Venezuela y algunas actualizaciones normativas del Perú, fue editado por Editorial Jurídica Venezolana con prólogo de Allan Brewer-Carias, el mismo año fue dicha obra también editada en Lima, Perú, por la Editorial Palestra.

109 ZúñIgA URBINA, Francisco. “Derecho Procesal Constitucional. El aporte de Domingo García Belaúnde a una nueva disciplina", en Palomino Manchego, José (Coord.) (2005). El Derecho Procesal Constitucional peruano. Estudios en Homenaje a Domingo García Belaúnde. Tomo II (Lima, Ed. Jurídica Grijley), p. 1423.

110 ZÚÑIGA URBInA, Francisco (2005). “Derecho Procesal Constitucional. El aporte de Domingo García Belaúnde a una nueva disciplina", en Palomino Manchego, José (Coord.) El Derecho Procesal Constitucional peruano. Estudios en Homenaje a Domingo García Belaúnde. Tomo II. Ed. Jurídica Grijley, Lima, p. 1424.

111 ZúÑIGA URBINA, Francisco. “Derecho Procesal Constitucional. El aporte de Domingo García Belaúnde a una nueva disciplina", en Palomino Manchego, José (Coord.) (2005). El Derecho Procesal Constitucional peruano. Estudios en Homenaje a Domingo García Belaúnde. Tomo II (Lima, Ed. Jurídica Grijley), p. 142. 
En Bolivia, el primer texto que conocemos que se refiera al derecho procesal constitucional es la obra colectiva Derecho procesal constitucional boliviano, editado por la Academia Boliviana de Estudios Constitucionales en Santa Cruz, en 2002; a partir de dicho hito histórico se han desarrollado diversas obras sobre la materia, como el libro de José Decker M orales, Derecho Procesal Constitucional, editado en Cochabamba, en 2002; y el libro del ex magistrado del Tribunal Constitucional Boliviano, Rene Baldivieso Guzmán, Derecho Procesal Constitucional (Ind. Gráficas Sirena, Santa Cruz de la Sierra, 2006).

Los trabajos más completos en la materia en Bolivia han sido desarrolladas por el académico y ex magistrado del Tribunal Constitucional, José Antonio Rivera Santiváñez, el que desarrolla la materia en su obra Jurisdicción Constitucional. Procesos constitucionales en Bolivia, cuya primera edición es de 2001 y su segunda edición actualizada de 2004 de Editorial Kipus, Cochabamba, en las cuales dedica el primer capítulo al desarrollo del concepto de derecho procesal constitucional, al contenido del derecho procesal constitucional y al derecho procesal constitucional en Bolivia. En 2007, el mismo autor ha editado su libro Temas de derecho procesal constitucional, en que recopila diversos trabajos y artículos ya publicados con anterioridad sobre diversos ámbitos e instituciones del derecho procesal constitucional.

\section{LAS REFLEXIONES AISLADAS SOBRE EL DERECHO PROCESAL CONSTITUCIONAL EN ALGUNOS PAÍSES EUROPEOS}

En Italia, la utilización del vocablo derecho procesal constitucional, según ha determinado García Belaúnde, fue utilizada por Renzo Provinciali, en 1959, sin realizar mayores precisiones. Es Gustavo Zagrebelsky, el que desarrollará un análisis de mayor contenido del tema en su obra La Giustizia Costitucional en 1988, y más recientemente en su libro "¿Derecho Procesal Constitucional? y otros ensayos de justicia constitucional" (Ed. FUNDAp, México, 2004).

A simismo, Antonio Ruggieri y Antonio Spadaro, en su libro Liniamenti de "Giustizia Costituzionale", Giappichelli Editore, Torino, 2001, consideran como equivalente las expresiones "justicia constitucional" y "derecho procesal constitucional", siendo dichos contenidos, para los autores, una parte o rama del derecho constitucional.

En España, el vocablo es utilizado por primera vez por José Almagro Nocete en un artículo denominado "Tres breves notas sobre Derecho procesal constitucional" publicado por la Revista de Derecho Procesal Latinoamericana, de Madrid, en 1979; en dicha obra señala que "[...] el Derecho Procesal, recibe del Derecho Constitucional la positivización de los principios y reglas que inspiran y limitan el desarrollo legislativo en materia procesal. Pero, a su vez, el Derecho Constitucional, en cuanto a objeto de tutela jurisdiccional, recoge del derecho procesal las técnicas que permiten la primacía efectiva de la Constitución en supuestos de controversia. Al primer conjunto de normas le he denominado Derecho Constitucional procesal. Al segundo, Derecho Procesal Constitucional. El "bloque" normativo integrante del Derecho Constitucional Pro- 
cesal está formado exclusivamente, por preceptos constitucionales y su fin es la fijación, con rango constitucional, de determinados principios y reglas reguladoras del Poder Judicial y de las garantías procesales básicas. En cambio, no todos, ni la mayoría de los preceptos que forman el Derecho Procesal Constitucional tienen rango constitucional, porque lo que caracteriza a este conjunto normativo no es el rango de las normas sino la peculiaridad del objeto sobre el que versa el proceso". ${ }^{112}$

A su vez, Domingo González Deleito en su libro Tribunales constitucionales, organización y funcionamiento, señala que "por derecho procesal constitucional ha de entenderse la rama del derecho procesal que estudia y regula las cuestiones derivadas de la inconstitucionalidad de las leyes, de las violaciones de los derechos y libertades proclamadas en los textos constitucionales". ${ }^{113}$

Sin embargo, el autor que en España desarrolla un estudio sistemático en la materia es el administrativista Jesús González Pérez, en su obra Derecho Procesal Constitucional, editada por Civitas, Madrid, 1980, la cual se centra en los procesos constitucionales españoles. Para González Pérez, una verdadera jurisdicción constitucional existe sólo cuando ella es ejercida por órganos independientes de la organización judicial. ${ }^{114}$ Para el autor, el derecho procesal constitucional está conformado por " [... ] el conjunto de normas que regulan el proceso constitucional. [... ] luego el derecho procesal constitucional será el conjunto de normas referente a los requisitos, contenidos y efectos del proceso constitucional". ${ }^{115}$ Dicha perspectiva no ha tenido mayor desarrollo académico en la doctrina ni en la enseñanza universitaria, donde los contenidos son analizados como Jurisdicción Constitucional en los planes de estudio de pre y postgrado, dentro del ámbito del derecho constitucional.

En Alemania, es Peter Häberle el que utiliza y analiza el concepto de derecho procesal constitucional en 1976 en un ensayo que se encuentra traducido al español en el texto Nueve ensayos constitucionales y una lección jubilar, editado en Lima, 2004, en la que sostiene que el derecho procesal constitucional no es más que un derecho constitucional concretizado. A su vez, Christian Pestalozza desarrollará su obra Verfasungsprozessrecht, M unchen, 1991, donde analiza los diversos procesos constitucionales a nivel Federal y de los Lander alemanes, donde en la parte introductoria hace algunas apreciaciones generales sobre el derecho procesal constitucional.

\footnotetext{
112 Almagro Nosete, José (1979). "Breves notas sobre el derecho procesal constitucional", en Revista de Derecho Procesal Iberoamericana, EDERSA Madrid, p. 684.

113 González Deleito, Domingo (1980). Tribunales constitucionales, Organización y funcionamiento. Manuales universitarios españoles, IX. Ed. Tecnos, Madrid, p. 12.

114 González Pérez, Jesús (1980). Derecho Procesal Constitucional (Madrid, Ediciones Civitas), p. 75.

115 González Pérez, Jesús (1980). Derecho Procesal Constitucional (Madrid, Ediciones Civitas), p. 49.
} 


\section{CONSIDERACIONES FINALES}

De acuerdo a todos los elementos analizados, puede sostenerse que el Derecho Procesal Constitucional es así una disciplina jurídica, cuyo desarrollo científico y académico se ha concretado en latinoamericana como hemos podido comprobar en este estudio, todo ello teniendo en consideración su desarrollo doctrinal, las publicaciones jurídicas especializadas, los encuentros y seminarios académicos internacionales y nacionales dedicados a la materia, como asimismo las instituciones dedicadas a la investigación y enseñanza de la materia, tanto en pre como post-grado.

A su vez, es posible determinar sus antecedentes temporales, positivos, personales y doctrinales, los que hemos precisado.

En el ámbito temporal los antecedentes remotos se encuentran en el Habeas Corpus Act inglés como primera garantía de los derechos fundamentales con una estructura y regulación desarrollada, como es posible situar la sentencia de la Corte Suprema de los Estados Unidos de 1803 como un antecedente jurisprudencial determinante en el nacimiento de la supremacía constitucional y el control de constitucionalidad difuso, como a su vez, será la Constitución y Tribunal Constitucional austriaco de 1920, el que con mayor fuerza será el antecedente y base de derecho positivo sobre el cual se desarrolla la supremacía constitucional y el control de constitucionalidad en Europa, además del desarrollo de la jurisdicción constitucional concentrado en un tribunal especial y fuera del poder judicial.

En el ámbito personal el nomen iuris se debe a Niceto Alcalá-Zamora y Castillo, al cual contribuirán en su desarrollo Calamandrei, Cappelletti, Couture y Kelsen. A simismo, es punto pacífico reconocer al maestro Héctor Fix Zamudio su conceptualización científica y el desarrollo de su contenido fundamental, al cual han contribuido con distintos énfasis y peculiaridades diversos constitucionalistas y procesalistas fundamentalmente latinoamericanos en el último tercio de siglo y los inicios del siglo XXI.

Debemos reconocer la existencia de diversas aproximaciones metodológicas y enfoques producto de su conceptualización como disciplina que forma parte del derecho procesal, del derecho constitucional o su reconocimiento como disciplina que recibe aportes y contenidos de ambas disciplinas, lo que independientemente de las matizaciones existentes en la materia hay un denominador común que es el estudio y análisis de la tutela jurisdiccional de la Constitución y de los derechos fundamentales, a partir de los valores, principios y normas constitucionales, a través de jurisdicciones especiales o no, con procesos y procedimientos constitucionales que tienen características peculiares y fuertemente diferenciados de aquellos de carácter civil, desarrollando una interpretación constitucional. Todo ello, sin perjuicio de apreciarse distintos códigos lingüísticos según el enfoque metodológico y la opción adoptada por el investigador o académico, frente a lo cual pareciera más conveniente el desarrollo de un pluralismo metodológico, ya que es la vía que potencia y enriquece la disciplina, teniendo presente que el derecho es en sus bases una unidad. Aun quienes plantean 
con mayor fuerza el método de enfoque esencialmente procesalista, deben reconocer las peculiaridades y autonomía del derecho procesal constitucional, con instituciones con perfiles propios y su determinación por los principios y normas constitucionales, especialmente cuando existe la presencia de un Tribunal Constitucional, lo cual requiere un rescate del derecho procesal constitucional de los enfoques rígidos del derecho procesal y del derecho constitucional, ya que existe una recíproca influencia entre los contenidos sustanciales de la Constitución y del proceso peculiar de carácter constitucional, que tiene un estatus constitucional por la fuente de la cual emana y por los principios y normas a las cuales debe servir, como la ductibilidad propia que debe tener siempre la jurisdicción constitucional de adecuación al respectivo sistema constitucional, sin perjuicio de reconocer al órgano de jurisdicción constitucional una relativa autonomía de generación de normas procesales constitucionales producto de sus propias sentencias y de la interpretación realizada de las normas que le vienen dadas por la Carta Fundamental además del desarrollo de prácticas y costumbres específicas de cada jurisdicción constitucional.

Debe reconocerse que las jurisdicciones constitucionales gozan de una garantía para perfeccionar e interpretar su propio derecho procesal, desarrollar sus propias interpretaciones y desarrollar pautas interpretativas específicamente constitucionales y enfoques hermenéuticos o de interpretación propios de la Constitución, con una fuerte tendencia a una interpretación evolutiva o dinámica

Desde la perspectiva del contenido hay consenso sobre contenidos mínimos o básicos, pero matizaciones más o menos pronunciadas sobre otras materias que serían parte del contenido de la disciplina y que requieren de ser dialogadas y consensuadas, estamos ante una disciplina aún en formación y, por tanto, no consolidada.

\section{BIBLIOGRA FÍA}

Abad Yupanqui, Samuel y otros (2003). Código Procesal Constitucional. Anteproyecto y Legislación vigente (Lima, Palestra Editores).

A bad Yupanqui, Samuel y otros (2004). Código Procesal Constitucional. Comentarios, exposición de motivos, Dictámenes (Lima, Palestra Editores).

A bad Yupanqui, Samuel (2004). Derecho Procesal Constitucional (Lima, Ed. Gaceta Jurídica).

A cademia Boliviana de Estudios Constitucionales (2002). Derecho Procesal Constitucional boliviano. Santa Cruz.

Alcalá-Zamora y Castillo, Niceto (1944). Ensayos de derecho procesal civil, penal y constitucional (Buenos Aires, Ed. de la Revista de Jurisprudencia Argentina S.A.).

A lcalá-Zamora y CAstLlo, Niceto (1991). Proceso, autocomposición y autodefensa (contribución a los fines del proceso). Primera edición, México, 1947, 3a edición, (M éxico, D.F. Ed. UNAM ).

A LDUNATE, Eduardo (1997). “El derecho procesal constitucional desde la perspectiva de la Teoría Constitucional". En Revista de Derecho de la Universidad Católica de Valparaíso $\mathrm{N}^{\circ}$ XVIII (Valparaíso, Universidad Católica de Valparaíso). 
A lmagro Nosete, José (1979). "Breves notas sobre el derecho procesal constitucional", en Revista de Derecho Procesal Iberoamericana (M adrid, EDERSA).

AnayA, Salvador Enrique (2004). A plicación de la Constitución y Derecho Procesal Constitucional, en Castañeda Otsu, Susana Ynés (Coord.). Derecho procesal Constitucional, Tomo I, Segunda edición (Lima, Jurista Editores).

Araujo Cintra, Antonio Carlos de; Pellegrini Grinover, Ada y Rangel Dinamarco, Candido (2006). Teoria Geral do Processo (Sao Paulo, Malheiros Editores).

Asbún, Jorge en respuesta a encuesta en García Belaúnde, Domingo y Espinosa-Saldaña Barrera, Eloy (Coords.). (2006). Encuesta sobre Derecho Procesal Constitucional (M éxico, D.F. Ed. Porrúa e Instituto M exicano de Derecho Procesal Constitucional).

Astudillo, César (2006). "Doce tesis en torno al Derecho Procesal Constitucional", en Revista Justicia Constitucional, Año II N 4, julio-diciembre de 2006 (Lima, Ed. Palestra), pp. 133-181.

Baldivieso Guzmán, René (2006). Derecho Procesal Constitucional. Industrias Gráficas Sirena, Santa Cruz de la Sierra.

Barrios GonzÁlez, Boris (2002). Derecho Procesal Constitucional. Segunda edición (Panama, Portobelo).

Bidart CAmpos, Germán (1987). La interpretación y el control constitucionales en la jurisdicción constitucional. Ediar, Buenos Aires.

Bordali, Andrés (2002). Temas de Derecho procesal constitucional (Santiago, Ed. Fallos del Mes - Universidad Austral de Valdivia).

CalamandRel, Piero (1962). Estudios sobre el proceso civil, Buenos Aires.

Calamandrel, Piero (1968). "La Illegitimita costituzionale delle leggi nel processo civile", en Opere Giuridiche, vol. III (Napoli, Morano).

Calam andrei, Piero. Derecho Procesal Civil. Trad. de Santiago Sentís M elendo, Ed. Ejea, Buenos Aires, 1986.

CAPPELLetTI, M auro (1961). La jurisdicción constitucional de la libertad (con referencia a los ordenamientos alemán, suizo y austriaco). (M éxico, Instituto de Derecho Comparado - UNAM, Imprenta Universitaria).

CAPPELletTI, Mauro (1975). El control de constitucionalidad de las leyes en el Derecho Comparado. Quinta edición (Milán, Giuffrè Editores).

Cappelletr, Mauro (1984). "Necesidad y legitimidad de la justicia constitucional, en Tribunales constitucionales europeos y derechos fundamentales (Madrid, Centro de Estudios Constitucionales), pp. 599-662.

Castañeda O tsu, Susana Ynés (Coord.) (2004). Derecho Procesal Constitucional, Tomo I, Segunda edición (Lima, Jurista Editores).

Cattoni, Marcelo (2001). Direito Processual Constitucional (Belo Horizonte, Ed. Mandamentos).

Colombo Cam pbell, Juan (2002). "Funciones del Derecho Procesal Constitucional". Revista lus et Praxis, Vol. $8 \mathrm{~N}^{\circ} 2$, pp. 11-69 (Talca, Facultad de Ciencias Jurídicas y Sociales, Universidad de Talca).

Colombo Campbell, Juan, en Prólogo fechado en diciembre de 2002 al libro de Bordalí, Andrés, Temas de Derecho procesal constitucional (Santiago, Ed. Fallos del Mes Universidad Austral de Valdivia).

Colombo Cam pbell, Juan (2007). El debido proceso constitucional. Ed. Porrúa, México. 
Couture, Eduardo (1978). "Las garantias constitucionales del proceso civil”, en Estudios de Derecho Procesal Civil. Tomo I. Segunda edición. Editorial Depalma, Buenos Aires.

Dantas, Ivo (2003). Constituiçao e Processo. Introdução ao Direito Processual Constitucional. Juruá Editora, Curitiba.

Decker M orales, José (2002). Derecho Procesal Constitucional, Cochabamba.

Escobar Fornos, Iván (1999). Derecho Procesal Constitucional (M anagua, Ed. Hispamer). Escobar Fornos, Iván (2005). Introducción al Derecho Procesal Constitucional (M éxico, Ed. Porrúa).

Espinosa-Saldaña Barrera, Eloy (2004). Código Procesal Constitucional. Serie Derechos y Garantías (Lima, Ed. Palestra).

Espinosa-Saldaña BARRERA, Eloy (Coord) (2005). Derechos fundamentales y Derecho Procesal Constitucional (Lima, Jurista Editores).

ETo CRUz, Gerardo (2006). En respuesta a cuestionario en García Belaúnde, Domingo y Espinosa-Saldaña Barrera, Eloy (Coords.). Encuesta sobre Derecho Procesal Constitucional, (M éxico, D.F., Ed. Porrúa e Instituto M exicano de Derecho Procesal Constitucional).

Fernández Rodriguez, José Julio (2006). En respuesta a encuesta en García Belaúnde, Domingo y Espinosa-Saldaña Barrera, Eloy (Coords.). Encuesta sobre Derecho Procesal Constitucional (M éxico, Ed. Porrúa e Instituto M exicano de Derecho Procesal Constitucional).

Ferrer M ac-Gregor, Eduardo (Coord.) (2004). Derecho Procesal Constitucional. Cuatro volumenes (M éxico, Ed. Porrúa).

Ferrer M Ac-Gregor, Eduardo (2008). Derecho Procesal Constitucional (M adrid, Ed. Marcial Pons).

FerRer M AC Gregor, Eduardo (2006). En respuesta a encuesta en García Belaúnde, Domingo y Espinosa-Saldaña Barrera, Eloy (Coords.). Encuesta sobre Derecho Procesal Constitucional (México, Ed. Porrúa e Instituto Mexicano de Derecho Procesal Constitucional).

FIX ZAMUDIO, Héctor (1955). La garantía jurisdiccional de la Constitución mexicana (ensayo de una estructuración procesal del amparo) (México. Facultad de Derecho, UNAM).

FIX Zamudio, Héctor (1956). "La aportación de Piero Calamandrei al Derecho Procesal Constitucional", en Revista de la Facultad de Derecho de México, Tomo VI, N²4, octubre-diciembre de 1956.

Fix-Zamudio, Héctor (1964). El juicio de Amparo (M éxico, Editorial Porrúa).

FIX-Zamudio. Héctor (1995). "Jurisdicción constitucional y protección de los derechos fundamentales en América Latina", en Anuario de Derecho Constitucional Latinoamericano $\mathrm{N}^{\circ} 1$ (M edellín, CIEDLA-Fundación Konrad Adenauer).

Fix-ZAmudio, Héctor (2002). Introducción al Derecho Procesal Constitucional (Querétaro, Ed. FUNDAp).

Fix-Zamudio, Héctor (2003). "Breves reflexiones sobre el concepto y contenido del derecho procesal constitucional", en Ferrer M ac-Gregor, Eduardo. Derecho procesal constitucional. Tomo I. Tercera edición (M éxico, Ed. Porrúa). 
Fix Zamudio, Héctor. En respuesta a encuesta en García Belaúnde, Domingo y EspinosaSaldaña Barrera, Eloy (Coords.) (2006). Encuesta sobre Derecho Procesal Constitucional (M éxico, Ed. Porrúa e Instituto M exicano de Derecho Procesal Constitucional). García Belaúnde, Domingo (1998). Derecho Procesal Contitucional (Trujillo, Ed. Marsol). García Belaúnde, Domingo (2003). De la jurisdicción constitucional al Derecho Procesal Constitucional. Cuarta edición corregida y aumentada (Lima, Ed. Grijley).

García Belaúnde, Domingo y Espinosa-Saldaña Barrera, Eloy (Coords.) (2006). Encuesta sobre Derecho Procesal Constitucional (M éxico, Ed. Porrúa, e Instituto M exicano de Derecho Procesal Constitucional).

García Belaúnde, Domingo (2008). El derecho procesal constitucional en perspectiva (M éxico, Ed. Porrúa).

González Deleito, Domingo (1980). Tribunales Constitucionales, Organización y funcionamiento. M anuales Universitarios Españoles, IX (M adrid, Ed. Tecnos).

González Montenegro, Rigoberto (2003). Curso de Derecho Procesal Constitucional. Segunda edición (Panamá, Litho Editorial Chen).

González Pérez, Jesús (1980). Derecho Procesal Constitucional (M adrid, Ediciones Civitas). González Pérez, Jesús (2006). En respuesta a encuesta en García Belaúnde, Domingo y Espinosa-Saldaña Barrera, Eloy (Coords.) Encuesta sobre Derecho Procesal Constitucional (M éxico, Ed. Porrúa e Instituto M exicano de Derecho Procesal Constitucional).

Gozaíni, Osvaldo Alfredo (1995). El derecho procesal constitucional y los derechos humanos (vínculos y autonomías) (M éxico Ed. UNAM).

Gozaínı, Osvaldo Alfredo (1999). Derecho Procesal Constitucional (Buenos Aires, Ed. de Belgrano).

Gozaínı, Osvaldo Alfredo (2006). Introducción al Derecho Procesal Constitucional (Buenos Aires, Rubinzal-Culzoni Editores).

GozAínı, Osvaldo. En respuesta a encuesta en García Belaúnde, Domingo y EspinosaSaldaña Barrera, Eloy (Coords.) (2006). Encuesta sobre Derecho Procesal Constitucional (M éxico, Ed. Porrúa e Instituto M exicano de Derecho Procesal Constitucional).

HÄBERLE, Peter (2004). "El derecho procesal constitucional como derecho constitucional concretizado frente a la judicatura del Tribunal Constitucional", en Nueve ensayos constitucionales y una lección jubilar (Lima, Palestra Editores).

HäBERLE, Peter (2005). El Tribunal Constitucional como Tribunal ciudadano. El recurso constitucional de amparo (M éxico, Ed. FUNDAp).

Hamilton Siqueira, Paulo (2006). Direito processual constitucional (Sao Paulo, Editora Saraiva).

Henao Hidrón, Javier (2003). Derecho procesal Constitucional. Protección de los derechos constitucionales (Bogotá, Ed. Temis).

Hernández Valle, Rubén (1995). Derecho Procesal Constitucional (San José, Ed. Juricentro). Hernández Valle, Rubén (2006). En respuesta a encuesta en García Belaúnde, Domingo y Espinosa-Saldaña Barrera, Eloy (Coords.) Encuesta sobre Derecho Procesal Constitucional (M éxico, Ed. Porrúa e Instituto M exicano de Derecho Procesal Constitucional). HITTERS, Juan Carlos. "El Derecho procesal constitucional", en Ferrer Mac-Gregor, Eduardo. Derecho procesal Constitucional. Tercera edición, Tomo I (M éxico, Ed. Porrúa). 
KeLSEN, Hans (1928). “La garantie jurisdictionelle de la Constitution (La justice constitutionnelle)", en Revue de Droit Public en France et a l'Etranger, París, pp. 52-143. LANDA, César (2004). Teoría del derecho procesal constitucional (Lima, Ed. Palestra).

Manilı, Pablo Luis. "Perfil del derecho procesal constitucional", en Palominos Manchego, José (Coord.) (2005). El Derecho Procesal Constitucional Peruano. Estudios en Homenaje a Domingo García Belaunde. Ed. Jurídica Grijley. Tomo I, Lima, pp. 145-164.

M ANILI, Pablo Luis (Coord.) (2005). Derecho procesal constitucional (Buenos Aires, Ed. Universidad de Buenos Aires).

Masciotra, Mario (Director) y Carelli, Enrique (Coord.) (2006). Derecho Procesal Constitucional (Buenos Aires, Ed. Ad-Hoc).

Mooney, Alfredo (2002). Derecho Procesal Constitucional (Córdoba, Ediciones de la Docta).

Mooney, Alfredo (2004-2005). Elementos de Derecho procesal constitucional, tomos I y II (Córdoba, Ed. Advocatus).

Morello, Augusto (1998). Constitución y Proceso (Buenos Aires-La Plata, Librería Editora Platense).

Nogueira A lcalá, Humberto (Coord.) (2009). La Ciencia del Derecho Procesal Constitucional. Estudios en homenaje a Héctor Fix-Zamudio, en sus 50 años como investigador del Derecho. Homenaje chileno (Santiago, Ed. Librotecnia).

Nogueira Alcalá, Humberto (2005). Justicia y Tribunales Constitucionales en América del Sur. Prólogo de Néstor Pedro Sagüés (Santiago, Ed. LexisNexis). Hay edición actualizada en Venezolana con Prólogo de Allan R. Brewer Carías. Editorial Jurídica Venezolana, Caracas, 2006. Hay edición peruana, Ed. Palestra, Lima, 2006.

Nogueira Alcalá, Humberto, en respuesta a Encuesta en García Belaúnde, Domingo y Espinosa-Saldaña Barrera, Eloy (Coords.) (2006). Encuesta sobre Derecho Procesal Constitucional (M éxico, Ed. Porrúa e Instituto M exicano de Derecho Procesal Constitucional).

Olano García, Hernán Alejandro (2004). Derecho Constitucional Orgánico. Estructura y Funciones del Estado (Bogotá, Ed. Doctrina y Ley Ltda.).

Oliveira Baracho, José Alfredo de (2006). Direito Processual Constitucional (Belo Horizonte, Ed. Fórum).

Ovalle Favela, Jorge. En respuesta a encuesta en García Belaúnde, Domingo y EspinosaSaldaña Barrera, Eloy (Coords.) (2006). Encuesta sobre Derecho Procesal Constitucional (México, Ed. Porrúa e Instituto Mexicano de Derecho Procesal Constitucional).

Palominos Manchego, José (Coord.) (2005). El Derecho Procesal Constitucional Peruano. Estudios en Homenaje a Domingo García Belaúnde. Dos tomos (Lima, Ed. Jurídica Grijley).

Quiroga León, Aníbal (2005). Derecho Procesal Constitucional y el Código Procesal Constitucional (Lima, ARA Editores).

Quiroga León, Aníbal. En respuesta a cuestionario en García Belaúnde, Domingo y Espinosa-Saldaña Barrera, Eloy (Coords.) (2006). Encuesta sobre Derecho Procesal Constitucional (México, Ed. Porrúa e Instituto Mexicano de Derecho Procesal Constitucional).

Ramos Tavarés, André (2006). Curso de Direito Constitucional, Cuarta edición (São Paulo, Editora Saraiva). 
REY CANTOR, Ernesto (1994). Introducción al derecho procesal constitucional (Controles de Constitucionalidad y legalidad) (Cali, Ed. Universidad Libre).

ReY CANTOR, Ernesto (2001). Derecho procesal constitucional, Derecho constitucional procesal, Derechos humanos procesales (Colombia, Ed. Ciencia y Derecho).

ReY CANTOR, Ernesto. "Derecho procesal constitucional en Colombia", en Ferrer MacGregor, Eduardo (Coordinador) (2002). Derecho Procesal Constitucional. Tomo III, Tercera edición (México, Ed. Porrúa).

RIvAs, A dolfo (director) y M achado Pelloni, Fernando (coord.) (2003). Derecho Procesal Constitucional (Buenos Aires, Ed. Ad-Hoc).

Rivera Santiváñez, José Antonio (2004). Jurisdicción constitucional. Procesos constitucionales en Bolivia. Segunda edición actualizada (Cochabamba, Ed. Kipus).

Rivera Santiváñez, José Antonio. En respuesta a encuesta en García Belaúnde, Domingo y Espinosa-Saldaña Barrera, Eloy (Coords.) (2006). Encuesta sobre Derecho Procesal Constitucional (M éxico, Ed. Porrúa e Instituto Mexicano de Derecho Procesal Constitucional).

Rodríguez, Domínguez, Elvito (2006). Manual de Derecho procesal constitucional. Tercera edición (Lima, Ed. Grijley).

SAGüÉs, Néstor Pedro (1989). Derecho procesal Constitucional. Recurso extraordinario (Buenos Aires, Ed. Astrea).

SAGüÉs, Néstor Pedro. "El código procesal Constitucional de la Provincia de Tucumán", en Bidart Campos, Germán (Coord.) (2000). El derecho constitucional del siglo XXI. Diagnóstico y perspectivas (Buenos Aires, Ed. Ediar).

SAgüÉs, Néstor Pedro. "El desarrollo del Derecho Procesal Constitucional: Logros y obstáculos", en Revista Hispanoamericana de Derecho, Ponencias del II Congreso Internacional de Derecho Constitucional y Procesal Constitucional, Huánuco, Universidad de Huánuco, Año 1, N², pp. 6 y ss.

SAGüÉs, Néstor Pedro (2006). Derecho procesal constitucional. Logros y obstáculos (Buenos Aires, Ed. Ad-Hoc y Konrad A denauer Stifftung).

SA GUÉs, Néstor Pedro, en respuesta a encuesta en García Belaúnde, Domingo y EspinosaSaldaña Barrera, Eloy (Coords.) (2006). Encuesta sobre Derecho Procesal Constitucional (M éxico Ed. Porrúa e Instituto M exicano de Derecho Procesal Constitucional).

SERRA, M aría Mercedes (1992). Procesos y recursos constitucionales (Buenos Aires, Ed. Depalma).

ZagrebelSKY, Gustavo (1990). “¿Diritto processuale costituzionale?”, en VV.AA. Giudizio a quo proumovimento del processo costituzionale (M ilano, Giufrè).

ZaGREBELSKY, Gustavo (2004). ¿Derecho procesal constitucional? y otros ensayos de justicia constitucional. Colegio de Secretarios de la Suprema Corte de Justicia de la Nación A.C. (México, FUNDAp).

Zúñiga Urbina, Francisco y PerRam ont S., Alfonso (2002). Introducción al Derecho Procesal Constitucional. Volumen I, Proceso de amparo de derechos fundamentales (Santiago, Ed. Facultad de Ciencias Jurídicas y Sociales, Universidad Central).

ZúNIIGA URBINA, Francisco. 2002. Elementos de Jurisdicción Constitucional. Dos tomos, (Santiago, Ed. Universidad Central de Chile). 
ZúÑIGA URBINA, Francisco. "Derecho Procesal Constitucional. El aporte de Domingo García Belaúnde a una nueva disciplina", en Palomino Manchego, José (Coord.) (2005). El Derecho Procesal Constitucional Peruano. Estudios en Homenaje a Domingo García Belaúnde. Tomo II (Lima, Ed. Jurídica Grijley), pp. 1421-1428.

ZúÑIGA URBINA, Francisco. En respuesta a encuesta en García Belaúnde, Domingo y Espinosa-Saldaña Barrera, Eloy (Coords.) (2006). Encuesta sobre Derecho Procesal Constitucional (México, Ed. Porrúa e Instituto Mexicano de Derecho Procesal Constitucional). 